NBER WORKING PAPER SERIES

\title{
EDUCATIONAL VOUCHERS AND CREAM SKIMMING
}

\author{
Dennis Epple \\ Richard Romano \\ Working Paper 9354 \\ http://www.nber.org/papers/w9354
NATIONAL BUREAU OF ECONOMIC RESEARCH
1050 Massachusetts Avenue
Cambridge, MA 02138 \\ November 2002
}

We thank Roland Benabou, Jonathan Hamilton, David Sappington, two anonymous referees, and workshop participants at the 1998 NBER Summer Institute, the MacArthur/Brookings Seminar, Cornell University, Johns Hopkins University, Princeton University, Stanford University, the University of British Columbia, the University of California at Los Angeles, the University of Kentucky, and the University of Pittsburgh for comments, and the National Science Foundation and MacArthur Foundation for support. The views expressed herein are those of the authors and not necessarily those of the National Bureau of Economic Research.

(C) 2002 by Dennis Epple and Richard Romano. All rights reserved. Short sections of text, not to exceed two paragraphs, may be quoted without explicit permission provided that full credit, including $₫$ notice, is given to the source. 
Educational Vouchers and Cream Skimming

Dennis Epple and Richard Romano

NBER Working Paper No. 9354

November 2002

JEL No. I2, H42

\section{ABSTRACT}

Epple and Romano (1998) show equilibrium provision of education by public and private schools has the latter skim off the wealthiest and most-able students, and flat-rate vouchers lead to further cream skimming. Here we study voucher design that would inject private-school competition and increase technical efficiencies without cream skimming. Conditioning vouchers on student ability without restriction on participating schools' policies fails to effect significantly cream skimming. However, by adding conditions like tuition constraints such as vouchers can reap the benefits of school competition without increased stratification. This can be accomplished while allowing voluntary participation in the voucher system and without tax increases.

Dennis Epple

Graduate School of Industrial Administration

Carnegie Mellon University

Posner Hall, Room 233C

Pittsburgh, PA 15213

and NBER

epple@andrew.cmu.edu
Richard Romano

Department of Economics

University of Florida

Gainesville, FL 32611-7140

Romanor@dale.cba.ufl.edu 


\section{EDUCATIONAL VOUCHERS AND CREAM SKIMMING}

\section{Introduction. Educational reform proposals that would use vouchers to enhance market}

provision of education are becoming about as frequent as state legislative sessions themselves. They stir passionate debate. Proponents of voucher systems espouse the power of market forces to weed out inefficient providers and increase school productivity. Critics forecast deleterious effects on poorer and less able students. One of their worries is that the higher quality schools will "cream skim" the richer and higher-ability students while consigning. less-fortunate students to weaker and weakened schools. This paper scrutinizes these claims.

We build on the model developed in Epple and Romano (1998) where peer effects make school quality dependent on the ability composition of a school's student body. We analyzed the simplest form of a voucher system, a fixed cash award to those who opted out of the public sector, and found some support for the concern about cream skimming. Such a voucher system promoted a quality hierarchy of schools, associated with income and ability stratification across the school hierarchy. This model admitted no productive inefficiencies, eliminating the possibility that vouchers might increase school productivity.

Here we examine general voucher systems that can condition student awards on student characteristics, while also allowing for productive inefficiencies in the delivery of education. We find support for both sides of the voucher debate. Since vouchers will stimulate private school competition, we affirm the obvious claim that technical inefficiencies can be reduced. More subtle is the connection between characteristics of the voucher system and the partition of students into schools. Voucher systems that place no restrictions on school tuition or admission policies will induce a school quality hierarchy, unless they are so (absurdly) radical as to largely

eliminate household income differences. In particular, vouchers that vary with student ability are not enough to eliminate stratification.

- Assuming a policy goal of vouchers is to provide a high and equal-quality education to all, we then examine how this might be enacted. A voucher that decreases with student ability 
and requires schools to accept the voucher as tuition can engender an equilibrium with technically efficient and equal-quality schools. The latter system will, however, either require large average vouchers and a high tax rate to finance them or mandatory participation in the system. Some households would be worse off with the latter voucher. This leads us to consider a voucher system with limited budget intended to improve schooling quality and household utility, and that allows students and schools to opt out. We show that productivity gains can be realized without increases in public finance of education, while avoiding cream skimming and improving outcomes for everyone or nearly everyone.

The related theoretical literature has focused mainly on flat-rate vouchers. One set of papers is primarily concerned with consequences of vouchers that partially offset the cost of private education on per student expenditure in public schools [Rangazas (1995), Epple and Romano (1996), and Hoyt and Lee (1998)]. Epple and Romano (1998) emphasizes peer effects and impacts on private-school tuition structure and composition, and is reviewed below. Caucutt (1998) pursues a similar analysis of vouchers to the latter, but allows households to randomize in school choice which resolves an existence problem we discuss later. Nechyba's (1999, 2000, forthcoming) model also has peer effects and further investigates the effects of voucher-induced migration on tax bases and local public provision in multiple jurisdictions. Manski's (1992) relatively early analysis of vouchers allowed rent seeking by public providers of education. McMillan (1998) develops a model where vouchers can worsen rent seeking in public schools. Another set of papers compares pure voucher regimes, i.e., with no public sector, to public provision alternatives (Bearse, Glomm, and Ravikumar, 1996) and some of these papers focus on dynamics [Glomm and Ravikumar (1995) and Gradstein and Justman (1997)].

This paper differs fundamentally in its departure from flat-rate systems and focus on voucher-system design. Nechyba (2000) and Caucutt (2002) examine consequences of targeting of vouchers to low-income types, one possible form of an alternative voucher design. ${ }^{1}$ Eden (1992) examines educational policy design in a two-type model of pure private provision with peer effects and educational achievement externalities. He derives results related to ours 
concerning voucher systems that are effective or ineffective in promoting mixing of students, with the underlying factor being the educational achievement externality. Critical to our results are differences in household income and demand for education, which are not elements of Eden's analysis. $^{2}$

Section 2 describes the theoretical model which extends Epple and Romano (1998) by allowing a student's achievement to vary not only with own and peer abilities, but also with educational expenditures. Section 3 develops equilibrium properties of the public-sector, private-sector equilibrium with no vouchers or with flat-rate vouchers. A computational model is also described that we employ to illustrate and quantify results throughout the paper. We show that as in Epple and Romano (1998) stratification or cream skimming is a real concern. Section 4 examines vouchers conditioned on student characteristics but without any restrictions on school policies. Motivated by the failure of realistic versions of the latter vouchers to promote competition without substantially increased stratification, Section 5 adds restrictions on school policies. A simple tuition restriction combined with ability-linked vouchers induces equalquality, competing, and technically efficient schools. Section 6 shows how these results carry over when students and schools can opt out of the system, including Pareto-improved outcomes relative to the (no-voucher) status quo. Section 7 concludes. An appendix contains some of the technical analysis.

\section{The Model.}

A. Household and Educational Technology. The model of educational provision builds on that in Epple and Romano (1998). ${ }^{3}$ Ignore vouchers for now, which are introduced below. Household income is denoted $y$, and each household has a student of ability $b$. The joint marginal distribution of ability and income in the population is denoted $f(b, y)$, and is assumed to be continuous and positive on its support, $S \equiv\left(0, b_{\max }\right] \times\left(0, y_{\max }\right]$. Let $\vec{b}$ and $\bar{y}$ denote the population means of ability and income. The household decision maker's utility function, $U(\cdot)$, is increasing in numeraire consumption and the educational achievement of the household's student, 
and twice differentiable in both arguments. Educational achievement, $a=a(q, b)$, is a nonnegative, twice-differentiable, and increasing function of the student's ability and the quality of the school attended, q. Achievement if no school is attended is zero (which will never occur in equilibrium). Let $y_{t} \equiv y(1-t)$ denote after-tax income, $t$ the income-tax rate, and $p$ tuition expenditure, the latter equal to zero if a public school is attended. Thus, $U=U\left(y_{1}-p, a(q, b)\right)$, with $U_{1}, U_{2}, a_{1}$, and $a_{2}$ all positive.

School quality is a twice differentiable, increasing, and strictly quasi-concave function of mean ability of peer students, $\theta$, and educational inputs per student, $I: q=q(\theta, I) .{ }^{4}$ Educational inputs per student equals per student expenditure above minimal or "custodial costs" as clarified below. While we use mean ability as the peer measure here, Epple, Newlon, and Romano (2002) show that the model can be generalized to the case where the peer quality measure is the mean of any increasing and differentiable function of $b$, without any qualitative effects on predictions. A concave function for example, implies gains from reducing variation in student ability in a school as from curriculum specialization.

$U$ is also assumed to satisfy everywhere the "single-crossing" condition:

$$
\partial\left[\frac{\partial \mathrm{U} / \partial \mathrm{q}}{\partial \mathrm{U} / \partial \mathrm{y}_{\mathrm{t}}}\right] / \partial \mathrm{y}_{\mathrm{t}}>0
$$

This condition corresponds to an income elasticity of demand for educational quality that is positive at all qualities for all types. Preferences for school quality might also depend on ability. We say preferences satisfy weak single crossing in ability if $\partial\left[\frac{\partial U / \partial q}{\partial U / \partial y_{t}}\right] / \partial b \geq 0$, which implies a non-negative ability elasticity of demand for quality. In our accompanying computational model and to illustrate our more general theoretical results, we adopt a Cobb-Douglas specification of the utility, achievement, and school-quality functions:

$$
U=\left(y_{t}-p\right) a(q, b) ; a(q, b)=q b^{\beta} ; q=I^{\omega} \theta^{\gamma} ; \beta, \omega, \gamma>0 .
$$

While (1) satisfies SCI, it embodies the "neutral" assumption of zero ability elasticity of demand: 


$$
\partial\left[\frac{\partial U / \partial Q}{\partial U / \partial y_{t}}\right] / \partial b=0 .
$$

A school's costs consist of custodial costs and expenditure on educational quality.

Letting $\mathrm{k}_{\mathrm{i}}$ equal the number of students in school $\mathrm{i}$, we assume school costs are given by:

$$
\mathrm{C}\left(\mathrm{k}_{\mathrm{i}}, \mathrm{I}_{\mathrm{i}}\right)=\mathrm{I}_{\mathrm{i}} \mathrm{k}_{\mathrm{i}}+\mathrm{V}\left(\mathrm{k}_{\mathrm{i}}\right)+\mathrm{F} ; \mathrm{V}^{\prime}>0 ; \mathrm{V}^{\prime \prime}>0
$$

Let $k_{i}^{*}$ denote the "efficient scale" of a school:

$$
\mathrm{k}_{\mathrm{i}}^{*} \equiv \operatorname{ARGMIN}\left[\mathrm{C}\left(\mathrm{k}_{\mathrm{i}}, \mathrm{I}_{\mathrm{i}}\right) / \mathrm{k}_{\mathrm{i}}\right]
$$

which is independent of $I_{i}$ in this specification. In our computational analysis, we assume schooling costs are quadratic in $\mathrm{k}_{\mathrm{i}}$,

$$
C\left(k_{i}, I_{i}\right)=C_{0}+\left(C_{1}+I_{i}\right) k_{i}+C_{2} k_{i}^{2}
$$

B. Public-Sector Schools. Public sector schools all follow the same policies and are homogeneous. ${ }^{5}$ They offer free admission to all.students. We assume no competition among schools within the public sector, while there is free entry among private schools. Hence, consistent with some ernpirical evidence, we allow public schools to be more costly to operate and less effective in delivering education than private schools. ${ }^{6}$ Specifically, we assume public school quality is given by $q_{p}(\theta, I)=q\left(\tau_{\theta} \theta, \tau_{I} I\right)$, where $\tau_{\theta}, \tau_{I} \leq 1$, at least one with strict inequality. ${ }^{\text {? }}$

Public-sector schooling is financed by a proportional income tax paid by all households, whether or not the household's child attends public school. The public sector chooses the integer number of schools to minimize the total cost of providing schooling, given the public-sector cost function and household choices of public or private schooling. ${ }^{8}$ The tax rate, hence per student educational expenditures in public school, is chosen by majority vote. When voting, households take the equilibrium selection of other students into public and private schools as given. Conditions for existence of voting equilibrium are developed in Epple and Romano (1996). 
These are satisfied in our computational model for example. Note that the homogeneity of public schools allows one to think of the public sector as one (typically large) public school.

C. Private-Sector Schools. Private-sector schools maximize profits and there is free entry and exit. ${ }^{9}$ Trivially, then, no cost-inefficient or ineffective private schools can be present in equilibrium (see footnote 7). It is the higher productivity of private schools, assumed to derive from free entry, that is the source of potential gains from vouchers in our model. However, our central findings would be unchanged even if public-school productivity rises to that of private schools. Student type is observable, implying tuition can be conditioned on ability and income as competition permits. Private schools are an example of clubs with "non-anonymous crowding" (Scotchmer and Wooders, 1987 and Scotchmer, 1997) because of the peer-group externality, and we model private-school behavior following the literature on competitive club economies. In particular, private schools maximize profits as utility takers (see Scotchmer, 1994), meaning they believe they can attract any student-type by offering admission at a tuition yielding at least the maximun utility the student could obtain elsewhere.

Let $\mathbf{n}$ denote the equilibrium number of private schools, and identify a private school with a subscript $i \in\{1,2, \ldots, n\}$. A subscript of 0 identifies "the" public school. In finding a private school's optimum, as well as market equilibrium, it is convenient to introduce an admission function, $\alpha_{i}(b, y) \in[0,1]$, that indicates the proportion of type $(b, y)$ in the population that school $i$ admits. Not admitting a type is equivalent to charging a prohibitive price, while admitted types will be charged a tuition such that they will attend the school in equilibrium. Note that any $\alpha_{0}(b, y) \in[0,1]$ is "optimal" for the public school; i.e., it admits any number of any type that wish to attend. Let $\mathrm{p}_{\mathrm{i}}(\mathrm{b}, \mathrm{y})$ denote the tuition function at school $\mathrm{i}$, with $\mathrm{p}_{0}(\mathrm{~b}, \mathrm{y}) \equiv 0 \forall(\mathrm{b}, \mathrm{y})$.

To describe the constraint on a private school's tuition function, let $U_{i}^{*}(b, y)$ denote the utility type (b,y) can obtain by choosing the best available alternative to school $\mathrm{i}$ in equilibrium:

$$
\begin{array}{r}
U_{i}^{*}(b, y) \equiv \underset{j \neq i}{\operatorname{MAX}} U\left(y_{t}-p_{j}(b, y), a\left(q_{j}, b\right)\right) \\
j \in\left\{0,1, \ldots, n ; \alpha_{j}(b, y)>0 \text { is optimal for } j\right\}
\end{array}
$$

Using the utility-taking assumption, private school i assumes it can attract any student for whom: 


$$
U\left(y_{1}-p_{i}(b, y), a\left(q_{i}, b\right)\right) \geq U_{i}^{*}(b, y)
$$

Let $\mathrm{p}_{\mathrm{i}}{ }^{*}\left(\mathrm{~b}, \mathrm{y}_{\mathrm{t}}, \mathrm{q}_{\mathrm{i}}\right)$ denote type $(\mathrm{b}, \mathrm{y})$ 's reservation price, obtained by solving for $\mathrm{p}_{1}$ when (6) holds as an equality. Charging any admitted type their reservation price is clearly optimal. We can then write private school i's optimization problem:

$$
\begin{array}{cc}
\operatorname{MAX} \pi_{\mathrm{i}}=\iint_{\mathrm{S}} \mathrm{p}_{\mathrm{i}}{ }^{*}\left(\mathrm{~b}, \mathrm{y}_{\mathrm{t}}, \mathrm{q}\left(\theta_{\mathrm{i}}, \mathrm{r}_{\mathrm{i}}\right)\right) \alpha_{\mathrm{i}}(\mathrm{b}, \mathrm{y}) \mathrm{f}(\mathrm{b}, \mathrm{y}) \mathrm{dbdy}-\mathrm{C}\left(\mathrm{k}_{\mathrm{i}}, \mathrm{I}_{\mathrm{i}}\right) \\
\text { s.t. } \\
\alpha_{\mathrm{i}}(\mathrm{b}, \mathrm{y}) \in[0,1] \forall(\mathrm{b}, \mathrm{y}) \in \mathrm{S} ; \\
\theta_{\mathrm{i}}=\frac{1}{\mathrm{k}_{\mathrm{i}}} \iint_{\mathrm{S}} \mathrm{b} \alpha_{\mathrm{i}}(\mathrm{b}, \mathrm{y}) \mathrm{f}(\mathrm{b}, \mathrm{y}) \mathrm{dbdy} ; \\
\text { and } & \mathrm{k}_{\mathrm{i}}=\iint_{\mathrm{S}} \int_{\mathrm{i}}(\mathrm{b}, \mathrm{y}) \mathrm{f}(\mathrm{b}, \mathrm{y}) \mathrm{dbdy}
\end{array}
$$

where the optimization is over $\alpha_{i}(b, y), I_{i}, \theta_{i}$, and $k_{i}$. The solution to (7) is presented below.

D. Equilibrium. The private/public equilibrium can be described by the following conditions.

$$
\begin{aligned}
& \mathrm{U}^{*}(\mathrm{~b}, \mathrm{y}) \equiv \operatorname{MAX} \mathrm{U}\left(\mathrm{y}_{\mathrm{t}}-\mathrm{p}_{\mathrm{i}}(\mathrm{b}, \mathrm{y}), \mathrm{a}\left(\mathrm{q}_{\mathrm{i}}, \mathrm{b}\right)\right) \quad \forall(\mathrm{b}, \mathrm{y}) \in \mathrm{S} \text {; } \\
& \mathrm{i} \in\{0,1, \ldots, \mathrm{n}\} \text { s.t. } \alpha_{\mathrm{i}}(\mathrm{b}, \mathrm{y})>0 \text { is optimal for } \mathrm{i}
\end{aligned}
$$

$\left[\theta_{\mathrm{i}}, \mathrm{I}_{\mathrm{i}}, \mathrm{k}_{\mathrm{i}}, \mathrm{p}_{\mathrm{i}}(\mathrm{b}, \mathrm{y}), \alpha_{\mathrm{i}}(\mathrm{b}, \mathrm{y})\right]$ are profit maximizing, $\mathrm{i}=1,2, \ldots, \mathrm{n}$;

$$
\pi_{\mathrm{i}}=0, \quad \mathrm{i}=1,2, . ., \mathrm{n}
$$

For all $(\mathrm{b}, \mathrm{y}) \in \mathrm{S}: \mathrm{p}_{0}(\mathrm{~b}, \mathrm{y})=0$ and $\alpha_{0}(\mathrm{~b}, \mathrm{y}) \in[0,1]$

$$
\mathrm{k}_{0}=\iint_{\mathrm{S}} \alpha_{0}(\mathrm{~b}, \mathrm{y}) \mathrm{f}(\mathrm{b}, \mathrm{y}) \mathrm{dbdy}
$$




$$
\begin{gathered}
q_{0}=q_{p}\left(\theta_{0}, I_{0}\right), \quad \theta_{0}=\frac{\tau_{\theta}}{k_{0}} \iint_{S} b \alpha_{0}(b, y) f(b, y) d b d y ; \\
\overline{t y}=k_{0} I_{0}+\underbrace{M I N}_{N \in\{1,2, \ldots\}}\left[N F+N V\left(k_{0} / N\right)\right] ; \\
\left(I_{0}, t\right) \text { is majority chosen; } \\
\sum_{i=0}^{n} \alpha_{i}(b, y)=1 \forall(b, y) \in S .
\end{gathered}
$$$$
\text { and }
$$

Condition UM summarizes utility maximization where $U^{*}(b, y)$ is equilibrium utility. Households choose a school that maximizes utility while taking as given school qualities, admission/tuition policies, and the tax rate. Profit maximization, IIM, has been discussed. No entry by or exit of private schools will occur if and only if the zero-profit condition ZII is satisfied. The public-school policies and outcomes are described by the five lines of condition PSP. The second to last line of PSP is the public-sector balanced-budget condition, where

$\overline{\mathrm{y}} \equiv \iint_{\mathrm{S}} \mathrm{yf}(\mathrm{b}, \mathrm{y}) \mathrm{dbdy}$ denotes both mean and aggregate income, the latter because we normalize the population to equal 1. The final condition is market clearance; all students attend a school since the public alternative always dominates dropping out.

E. Vouchers. We analyze several voucher systems, so there is some minor variation in how the equilibrium conditions must be extended. In each system, vouchers may be used only at private schools. Because public schools are tuition free and homogeneous (including equally inefficient), a voucher that increases public-school choice has no effects in our model. We assume throughout that the voucher system is exogenous and financed out of tax revenues, while maintaining public school per student expenditure on educational inputs at $\mathrm{I}_{0}$, the level majority chosen with no voucher. We choose to abstract from potential effects of vouchers on publicschooling expenditures to isolate effects on stratification that policy is less likely to anticipate. ${ }^{10}$ Let $S_{0}$ denote the subset of $S$ containing student types that attend public-sector schools, and $S_{R}$ 
the complement set of student types attending private-sector schools. ${ }^{11}$ The tax rate then satisfies the modified balanced-budget condition:

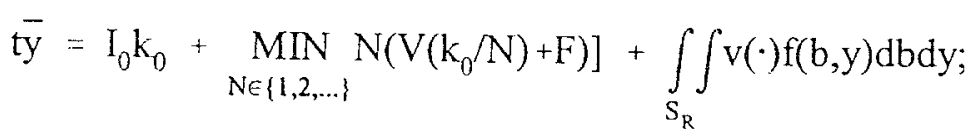

where $v(\cdot)$ denotes the amount of the voucher.

The first two voucher systems we analyze are a flat-rate system with $\mathrm{v}$ the same for every private-school student and a type-dependent system with $v=v(b, y)$ conditioned on type. In these analyses, we permit private schools complete freedom in their admission and tuition policies (i.e., they can charge more or less than the voucher). The intent is to analyze the pure effects of vouchers in an otherwise laissez-faire setting, with public schools if they continue to exist. ${ }^{12}$ For now, we require that private-school students take their voucher, which is not objectionable so long as $v>0$. We will analyze cases where $v<0$ for some types, and we will go on to analyze voluntary participation. In the analyses of the first two systems, letting $p_{1}$ denote the take-home tuition of private school $i$, the remaining modification to the equilibrium conditions is accomplished by adding $v(\cdot)$ to every type's after-tax income whenever they attend private school. ${ }^{13}$ For example, private school i's reservation price function becomes $\mathrm{p}_{\mathrm{i}}{ }^{*}\left(\mathrm{~b}, \mathrm{y}_{\mathrm{t}}+\mathrm{v}(\cdot), \mathrm{q}_{\mathrm{i}}\right)$. Intuitively, the effective income of private-school students is their after-tax income plus the amount of their voucher.

3. Flat-Rate Vouchers. The analysis here extends the findings in Epple and Romano (1998) where school quality varies only with student peer groups to educational expenditure variation. Hence, we will attempt to be brief. Equilibrium here serves as a benchmark for the analysis that follows. The analysis subsumes the case with no voucher.

A starting point for understanding the properties of equilibrium is to examine the profit maximum of a private school. Private school i's optimization can be described by the following conditions: 


$$
\begin{gathered}
\mathrm{p}_{\mathrm{i}}(\mathrm{b}, \mathrm{y})=\mathrm{p}_{\mathrm{i}}{ }^{*}\left(\mathrm{~b}, \mathrm{y}_{\mathrm{i}}+\mathrm{v}, \mathrm{q}_{\mathrm{i}}\right) \forall(\mathrm{b}, \mathrm{y}) \in \mathrm{S} ; \\
\iint_{\mathrm{S}} \frac{\partial \mathrm{p}_{\mathrm{i}}{ }^{*}}{\partial \mathrm{I}_{\mathrm{i}}} \alpha_{\mathrm{i}}(\mathrm{b}, \mathrm{y}) \mathrm{f}(\mathrm{b}, \mathrm{y}) \mathrm{dbdy}=\mathrm{k}_{\mathrm{i}} ; \\
\alpha_{\mathrm{i}}(\mathrm{b}, \mathrm{y})\left(\begin{array}{c}
=1 \\
\epsilon[0,1] \\
=0
\end{array}\right) \text { if } \mathrm{p}_{\mathrm{i}}{ }^{*}\left(\mathrm{~b}, \mathrm{y}_{\mathrm{t}}+\mathrm{v}, \mathrm{q}_{\mathrm{i}}\right)\left(\begin{array}{l}
> \\
= \\
<
\end{array}\right) \mathrm{EMC}_{\mathrm{i}}(\mathrm{b}) \quad \forall(\mathrm{b}, \mathrm{y}) \in \mathrm{S} ; \\
\operatorname{EMC}_{\mathrm{i}}(\mathrm{b}) \equiv \mathrm{I}_{\mathrm{i}}+\mathrm{V}^{\prime}\left(\mathrm{k}_{\mathrm{i}}\right)+\eta_{\mathrm{i}}\left(\theta_{\mathrm{i}}-\mathrm{b}\right) ;
\end{gathered}
$$

and

$$
\eta_{i}=\frac{1}{k_{i}} \iint_{S} \frac{\partial p_{i}^{*}}{\partial \theta_{i}} \alpha_{i}(b, y) f(b, y) d b d y=\frac{\partial q_{i} / \partial \theta_{i}}{\partial q_{i} / \partial I_{i}}
$$

Condition (8.1) indicates, again, that all students are charged their reservation price. Condition (8.2) is the Samuelsonian condition describing school i's choice of $L_{4}$. Condition (8.3) details the admission policy: Every type (b,y) is admitted whose reservation price exceeds their "effective marginal cost (EMC)" and no types are admitted whose reservation price is less than EMC. The effective marginal cost is defined in (8.4), equal to the resource cost of educating a type plus the cost of their peer externality in the school. The peer externality cost of a student equals the change in the peer measure from admitting the student $\left(\left[\mathrm{b}-\theta_{\mathrm{i}}\right] / \mathrm{k}_{\mathrm{j}}\right)$, multiplied by the shadow value of the peer quality measure $\left(k_{i} \eta_{i}\right)$. Using (8.5), one can think of the latter as the change in tuition necessary to retain students or the change in inputs necessary to maintain quality (and thus retain students). The peer "cost" is positive if $b<\theta_{i}$ and negative if $b>\theta_{i}$, and $E M C_{i}$ itself will be negative for students of ability sufficiently higher than the school's mean ability when such students exist.

Turning to market properties, the analysis is complicated by an existence problem. The existence problem is generic to club economics (see Scotchmer, 1994), derives from the fixed costs and integer number of schools, and is manifest in an inability to have all private schools' 
profits equal zero in general. Our resolution is to examine an "epsilon competitive equilibrium," that replaces the (IM) and (Zח) conditions with requirements that private schools are at local profit maxima (implying satisfaction of all first-order conditions), but allowing profit levels to differ from zero by a positive value $\epsilon$. Hence, entry (exit) will not occur unless $\pi_{i}>\epsilon\left(\pi_{i}<-\epsilon\right)$ for some private school, nor would an incumbent school pursue nonlocal changes in admission/tuition policies unless it could gain more than $\epsilon$. The "equilibrium" results reported in the rest of the paper apply to our approximate equilibrium as well as exact equilibrium $(\epsilon=0)$ when it exists. ${ }^{14}$

We employ findings from our computational model to illustrate and quantify the general theoretical properties of market equilibrium. We now summarize calibration of the computational model which builds on the computational model in Epple and Romano (1998). We extend that model to incorporate expenditure on inputs as well as differences in effectiveness and efficiency between public and private sectors. We also broaden the scope of that model to permit study of the differing voucher systems developed in this paper. The computational model entails a choice of joint density function for income and ability, utility and achievement functions, and cost functions for education.

Income and ability follow a joint lognormal distribution: $[\ln (b)]$ is distributed bivariate normal with mean $\left[\begin{array}{l}\mu_{\mathrm{b}} \\ \mu_{\mathrm{y}}\end{array}\right]$ and covariance matrix $\left[\begin{array}{rr}\sigma_{\mathrm{b}}^{2} & \rho \sigma_{\mathrm{b}} \sigma_{\mathrm{y}} \\ \rho \sigma_{\mathrm{b}} \sigma_{\mathrm{y}} & \sigma_{\mathrm{y}}^{2}\end{array}\right]$ Calibrating the marginal distribution of income to mean $(\$ 40,816)$ and median $(\$ 54,842)$ income in 1999 yields $\mu_{y}=10.62$ and $\sigma_{y}=$ .77 .

To calibrate the distribution of ability, we assume this distribution to be a primitive, i.e., independent of policy changes. We further assume that annual future earnings while employed equal normed achievement, $a_{N}$. The latter is obtained by raising the achievement function we adopt, $a=\theta^{\gamma}{ }_{1}^{\omega} b^{\beta}$, to the power $1 / \beta$ and multiply by a constant: $a_{\mathrm{N}} \equiv \Lambda \mathrm{I}^{\omega / \beta} \theta^{\gamma / \beta} \mathrm{b}$. Hence, normed achievement is measured in the same units as ability, and both are measured in dollars. ${ }^{15} \mathrm{We}$ assume the elasticity of achievement with respect to peer ability is $10 \%$ as large as the elasticity of achievement with respect to own ability: $\gamma / \beta=.1$. This estimate is consistent with recent 
empirical evidence of Ding and Lehrer (2001) but smaller than estimated by Henderson, Mieszkowski, and Sauvageau (1977), and, in this respect, a conservative estimate of the magnitude of peer effects. Our calibration of costs below, leads to setting $\gamma=\omega$. With this, parameters for the ability distribution are then chosen to give rise to an approximate steady-state equilibrium. That is, the distribution of normed achievement in each generation (approximately) replicates the distribution of income of the parent generation. A finai step adjusts for the ratio of workers per household to students per household (2.6 in 1990). The outcome of this calibration process is $\mu_{\mathrm{b}}=9.66$ and $\sigma_{\mathrm{b}}=.70$. Keep in mind that normed achievement can be interpreted as future income. We set $\rho=.4$, which equals the correlation between father and son earnings found by Solon (1992) and Zimmerman (1992). This completes the calibration of $f(b, y)$. ,

The combined utility-achievement function is assumed Cobb-Douglas (recall (1)). Cost per student in the U.S. in the year 2000 was approximately $\$ 7,000 .^{16}$ This cost is divided equally between custodial and discretionary inputs as the evidence suggests. ${ }^{17}$ Equilibrium that yields public choice of school expenditure of $\$ 7,000$ per student, with half being custodial costs, requires $\gamma=\omega=.03$. This and $\gamma / \beta=.1$ from above yield the calibrated utility/achievement function $U=\left(y_{t}-p\right) \theta^{.03} I^{03} b^{3}$.

We take the implied school-quality function $q=\theta^{.03} \mathrm{I}^{.03}$ (see (1)) described thus far as applying to private schools. For public schools, we modify that function to reflect their lower effectiveness $\left(\tau_{\theta}<1\right)$ and efficiency $\left(\tau_{1}<1\right)$. Hoxby $(2000)$ studies competitive effects on both school effectiveness and efficiency, and we base our calibration on her results. Her measure of public school competition is a Herfindahl index that is calculated using the proportions of students served by distinct districts in each metropolitan area. She finds that a one standard deviation increase in this measure of competition results in income gains of approximately $4 \%$ per student and schooling cost reductions on the order of $2 \%$. Thus, we calibrate $\tau_{\theta}=.96$ and $\tau_{I}$ $=.98$ so that normed achievement in a public school is $96 \%$ as high as normed achievement in a private school that has the same peer quality and spends $98 \%$ as much on inputs as the public school. 
The custodial cost function is assumed quadratic in $\mathrm{k}$, as specified in (4). We set $\mathrm{C}_{0}=$ $20.4, C_{1}=350$, and $C_{2}=23,000$. This cost function implies that $\mathrm{k}^{*}$ (the efficient scale) equals $3 \%$ of the student population and average custodial cost at the efficient scale equals $\$ 3,500$ per student.

To interpret the market equilibrium properties, refer to the computational examples illustrated in Figure 1, which are discussed in detail below. The solid lines in these panels, which we call "boundary loci," delineate the attendance sets of private schools and the public sector. For example, the five boundary loci in the upper left panel of Figure 1 delineate the attendance sets of the public sector and five private schools that arise in computed equilibrium with no voucher. Key equilibrium properties are summarized in Proposition 1.

Proposition 1. 1. Strict Hierarchy: A strict hierarchy of private schools results: $q_{n}>q_{n-1}>\ldots>q_{1}$. If $v=0$, public-sector schools have $q_{0}<q_{1}$, but not necessarily if $v>0$.

2. Pricing: a. Along a boundary locus between schools, $\mathrm{p}_{\mathrm{i}}=\mathrm{EMC}_{\mathrm{i}}(\mathrm{b})$ for private schools $(\mathrm{i} \neq 0)$; private school pricing along boundary loci depends only on ability.

b. In the interior of school i's admission space, $p_{i}>E C_{i}(b)$ for $i \neq 0 ;$ private-school pricing off boundary loci also depends on (effective) income.

c. Students choose the same schools that they would if the prices they faced of private schools equaled equilibrium $\mathrm{EMC}_{\mathrm{i}}(\mathrm{b}), \mathrm{i}=1,2, \ldots, \mathrm{n}$.

3. Stratification: a. Attendance is characterized by income stratification. In other words, for given ability, attendance at a higher quality school implies higher household income. ${ }^{18}$ b. If preferences satisfy weak single crossing in ability and $\eta_{h} \geq \eta_{n-1} \geq \ldots \geq \eta_{1}$, then stratification by ability (analogously defined) also characterizes school choice when $v=0$. Under these conditions but when $v>0$ and $q_{0}>q_{i}$ for some private school $i$, ability stratification may be violated between the public sector and lower-quality private schools.

Proof is in the appendix. Here we provide an intuitive discussion. The strict hierarchy among private schools in Proposition 1.1 reflects the normality of demand for educational quality 
and the associated willingness of higher-income types to spend more on inputs and to crosssubsidize higher-ability types to create better schools. The latter is likewise manifest in the discounting to ability in private schools in Proposition $1.2 \mathrm{a}$ and the stratification pattern in Proposition 1.3. The departure from EMC pricing in Proposition 1.2b derives from some market power that private schools have due to their discrete differences in quality, but has only income effects on the equilibrium allocation (Proposition 1.2c).

Given a non-negative ability elasticity of demand for school quality, we see in Proposition $1.3 \mathrm{~b}$ that ability stratification "usually" results; i.e., if higher-quality schools value ability by more. ${ }^{19}$ The combination of income and ability stratification yields downward sloping boundary loci. An exception to the latter is when vouchers induce the entry of one or some private schools of lower quality than public-sector schools. Such private schools provide negative net tuition to every student $(\mathrm{p}-\mathrm{v}<0)$, attracting students from poor households who trade off lower school quality for the fellowship. In the example with $\mathrm{v}=\$ 4,530$ shown in upper right panel of Figure 1, two such "bottom feeder" schools result. Note the upward sloping portions of the boundary loci between these two private schools and the public sector. ${ }^{20}$ Ability stratification between the public-sector and the adjacent lower-quality school fails here.

Fellowships, net and gross, can also be provided to relatively higher-ability students in private schools of higher quality than public schools with or without vouchers. Some students receive fellowships in every private school in the case with $v=0$ depicted in Figure 1 for example.

To provide a point of departure for our analysis of alternative voucher designs, consider further our computational findings with no voucher and the flat-rate voucher. With no voucher, the public sector serves $88.5 \%$ of the student population, and five private schools serve the remaining population. ${ }^{21}$ A voucher of $\$ 4,530$ per student would cover almost $65 \%$ of the $\$ 7,000$ expenditure per student in public schools. The resulting allocation, illustrated in the upper-right panel of Figure 1, has a public sector serving $31 \%$ of the student population and 25 private schools serving the remaining students. This voucher induces entry of eighteen schools of higher 
quality than the public sector and two schools of quality lower than the public sector (the latter the reason we chose to illustrate this level of the voucher).

A flat-rate voucher of $\$ 7,000$ per student covers the full cost of public-school education, and 35 private schools serve the entire student population in this case. The allocation of students across schools in the resulting equilibrium is illustrated in the bottom panel of Figure 1. We say that there is "cream skimming" when private-school admission of relatively able students is associated with worsening school qualities for other students, e.g., in the public sector. It is evident from Figure 1 that the flat-rate voucher induces cream skimming. We find that $\mathrm{q}_{0}$ declines as the voucher rises in spite of some eventual entry of some bottom-feeder schools (with temporary jumps up in $\mathrm{q}_{0}$ given their discrete entry). This decline in $\mathrm{q}_{0}$ results solely due to deterioration of the public-sector peer group as we have held fixed educational inputs per student in the public sector. ${ }^{22}$ The voucher equal to $\$ 4,530$ per student leads $53.4 \%$ of students to attend a lower quality school and thus have lower educational achievement relative to the no-voucher benchmark. The top panel of Table 1 shows mean percentage changes in normed achievement from the $\$ 7,000$ voucher by ability and income deciles. Although more efficient and effective private schools have supplanted the public sector, $57.8 \%$ of students are in lower quality schools and have lower achievement. ${ }^{23}$ As Figure 1 suggests and Table 1 confirms, achievement losses are experienced by students in low-income households and by low-ability students in middleincome households. These results echo findings reported in our prior work (Epple and Romano, 1998), which did not incorporate expenditure variation in the achievement function and did not allow for differences in effectiveness and efficiency of the private relative to the public sector.

We also calculate the compensating variation from the voucher. The top panel of Table 2 shows the mean ratio of compensating variation to income by deciles for the $\$ 7,000$ voucher relative to the no-voucher equilibrium. Effects on compensating variation are substantially different from those on educational achievement. Most of the sign differences between the effects on achievement and compensating variation derive from poor students who are willing to trade off educational quality for higher income. Comparing, for example, the first rows of the 
upper panels of Tables 1 and 2, we see that poor students of relatively high ability experience (sometimes substantial) gains in compensating variation while attending lower-quality schools with the $\$ 7,000$ voucher. These students are receiving fellowships (or increased fellowships) as the voucher leads to greater discounting to ability. In fact, $85 \%$ experience welfare gains from the voucher by the compensating-variation measure. ${ }^{24}$

While of interest to examine, compensating variation has drawbacks as a welfare measure here. Social externalities from education are likely to be present that compensating variation does not measure. Even without the latter, if the (empirically motivated) positive income elasticity of demand for educational quality built into our utility function is a result of capital market failures, then, again, compensating variation improperly measures welfare. Thus, we think it important to assess these alternatives both in their effects on educational achievement and utility (compensating variation). In addition, there is substantial variation in the effects on both compensating variation and achievement from the flat-rate voucher.

We think it is of clear interest to examine voucher aiternatives that might reap the benefits of school competition in a way that benefits everycne or nearly so. Ideally, a voucher program would result in increases in both measures for everyone. Obviously, any voucher that exacerbates stratification - that leads to cream skimming -- will fail by our criteria. How must such a voucher system be designed to avoid cream skimming?

\section{Type-Dependent Voucher Systems. A. Theoretical Analysis. The general form of a type-} dependent voucher allows it to vary with any household characteristic: $v=v(b, y)$. The main result here, is that, without also restricting school behavior, any type-dependent voucher that can be taken seriously will fail to inject significant competition without substantially increased stratification. If one wishes to impose voluntary participation of students, then $v(\cdot) \geq 0$ is required. Because it is simpler and we can make our point here more strongly without necessarily satisfying voluntary participation, we continue for now to require participation of all , students. The model is as in Section 2 with every household that chooses private school having effective income equal to $y_{t}+v(b, y)$ and with the modified budget constraint. 
The underlying theoretical result is stated in Proposition 2. Our interest is only in voucher systems that promote private-school competition. Hence, we assume henceforth an equilibrium with two or more private schools. As discussed further below, we can contrive voucher systems that reduce cream skimming via contraction of the private sector, but the latter runs counter to their purpose.

Proposition 2. Type-dependent voucher systems that preserve a nondegenerate joint distribution on effective income and ability engender a strict hierarchy of private-school qualities. ${ }^{25}$

The proof is a simple adaptation of the proof of Proposition 1.1 and is omitted. The intuition is as follows. The students who attend private schools have types distributed over $\left(y_{t}+v(b, y), b\right)$. If two private schools were of equivalent quality, then either schooi could increase profits by substituting students (aitracting some from the other school) so as to increase quality and the effective income of the student body, or by doing the reverse. The former substitution, for example, would allow a profit increase because the ex post richer student body would value the quality increase by more than would the ex ante poorer student body. Only if the voucher system were to eliminate almost completely income differences, i.e., only if $v(b, y)=\bar{y}_{t}-y_{t}+v^{*}(b)$ for appropriately chosen $v^{*}(b)$, could homogeneous private schools be induced. ${ }^{26}$ But such a draconian voucher system cannot be taken seriously.

If one converts income to effective income, then all the results regarding private schools and their students in Section 3 when $v=0$ apply. The private-school pricing and stratification results of Proposition 1 hold for example.

The peer-group externality in the value of schooling is central to the persistence of the hierarchy under realistic type-dependent voucher systems. Lower-ability students are relatively expensive to educate in our model because their presence in a school reduces quality and all students' willingness to pay to attend the school. One might surmise that a voucher that compensates for the externality cost could eliminate a hierarchy and prevent cream skimming. But the peer costs (the $\eta$ 's) vary with the schools' peer groups, including their household income levels, so the voucher must also nearly eliminate income differences; or, as shown below, 
constrain school behavior.

A type-dependent voucher system that eliminates a hierarchy by reducing the role of the private sector can be contrived. For example, a sufficiently negative voucher given to all would eliminate the private sector. But such a voucher would obviously stifle competition and reduce technical efficiencies.

Whether for realistic parameter values a voucher linked to ability could introduce substantial school competition without significant cream skimming is not obvious. We then examine this computationally.

B. Computational Analysis of a Type-Dependent Voucher. The type-dependent voucher we examine is of the form: $v(b)=v_{0}+.177(\bar{b}-b)$. This is the same form as EMC(b) assuming homogeneous schools each having the peer group with $\theta$ equal to the population mean ability. We caiculate .177 to be the shadow value of ability if the voucher leads to homogeneous schools. ${ }^{27}$ We let $v_{0}$ rise to the level of expenditure per student in the public sector $(\$ 7,000)$, which will be enough to eliminate it and is comparable to the $\$ 7,000$ flat-rate voucher. As Section 5 will clarify, we examine the type-dependent voucher that is independent of income of form necessary (but not sufficient as we will see!) to engender homogeneous schools.

Equilibria with the ability-dependent voucher are illustrated in Figure 2. To see whether the vouicher system promotes widespread gains, these may be compared to the benchmark novoucher equilibrium portrayed in the upper-left panel of Figure 1. The left panel of Figure 2 illustrates the equilibrium with the ability-dependent voucher having fixed component $\mathrm{v}_{0}=$ $\$ 4,530$. This voucher induces entry of five private schools with quality below that of the public school and four with peer quality above that of the public school. Relative to the flat-rate voucher of $\$ 4,530$, the increased entry at the lower end of the school quality hierarchy is because this voucher rewards low ability, with the opposite effects at the upper end of the school quality hierarchy. Because of the substantial entry at the lower end, the peer group in the public sector improves somewhat, with then small normed achievement gains of about $1 \%$ to those $64 \%$ of the 
population that remain in that sector. But those who enter the lower-end private schools lose in normed achievement, some very substantially. For example, the mean loss in normed achievement among those in the lowest decile of income and ability is $20 \%$ (though, of course, we know by revealed preference that their utilities rise). While $75 \%$ gain in educational achievement, one must keep in mind that $64 \%$ gain only the $1 \%$ and there are many who experience lower achievement.

We provide more detail about the effects of this voucher with $\mathrm{v}_{0}=\$ 7,000$, the resulting fully private equilibrium depicted in the right panel of Figure 2. Aside from the income effects deriving from some redistribution toward lower-ability students, the allocation in the right panel of Figure 2 is obviously quite similar to that in the lower panel of Figure 1 . Here $55 \%$ have lower achievement after introduction of this voucher, as compared to $54 \%$ with the $\$ 7,000$ flatrate voucher. In spite of the subsidy to lower-ability students, the voucher fails miserably to promote widespread educational gains. The middle panel of Table 1 provides detail on the changes in normed achievement. Comparing this to the top panel reveals that the effects on educationai achievement of the ability-dependent voucher differ little from those of the flat-rate voucher -- both adversely affect achievement of children in low-income households and lowability children in middle-income households.

The effects on compensating variation of this voucher are quite different from those of the flat-rate voucher as can be seen by comparing the middle panel of Table 2 to the top panel. Low-income households with low-ability students experience a welfare gain because the voucher is greater for low-ability students. Indeed, $95 \%$ of the population gains from this voucher relative to the no-voucher equilibrium. Obviously, however, the gains are not due to increased educational quality but to income redistribution.

\section{Tuition-Constrained Vouchers.}

Here and in the next section we show that vouchers combined with constraints on school 
behavior can accomplish our goals. We focus on a type-dependent voucher that requires schools to accept the voucher as tuition, allowing no extra charges or kickbacks. This is not the only alternative, however, as we will discuss.

Consider the ability-dependent voucher:

$$
v(b)=V^{\prime}(k+)+I_{v}+\eta_{v}(\bar{b}-b)
$$

where

$$
\eta_{v} \equiv \frac{q_{\theta}\left(\bar{b}, I_{v}\right)}{q_{I}\left(\bar{b}, I_{v}\right)} \text { with } I_{v} \text { such that } q\left(I_{v}, \bar{b}\right) \geq q_{p}\left(I_{0}, \bar{b}\right) \text {. }
$$

Every student attending private school receives such a voucher and any private school must accept the voucher as tuition for any student it admits. We continue to require participation until the next section, i.e., private-school students must accept the voucher. Private schools have complete discretion about whom to admit. Regarding the equilibrium conditions, the solution to the private-school profit-maximization problem in the presence of this tuition-constrained voucher is developed below. ${ }^{28}$

Note that the voucher equals EMC(b) assuming a private school with per student expenditure on quality-enhancing inputs equal to $I_{v}$ and with peer measure equal to the population mean ability. Note, too, that we have restricted $\mathrm{I}_{\mathrm{v}}$ such that the latter such private school would provide higher quality than a public school with peer measure equal to the population mean $\left(I_{v} \geq I_{0}\right.$ is sufficient). We show this voucher engenders homogeneous and competing private schools serving the entire population. An issue that arises in showing this is how students evaluate the public alternative, specifically the relevant peer group, when no public schools are present. We assume the public alternative is not considered in such cases, although other sensible assumptions give the same results as discussed below. 
Proposition 3. Under the tuition-constrained voucher $(9.1)-(9.2)$, equilibrium has: $1 / \mathrm{k}^{*}$ private schools, each with $k^{*}$ students, of quality $q_{v} \equiv q\left(\bar{b}, I_{v}\right)$ with $I=I_{v}$ and $\theta=\bar{b}$, and earning zero profits. No public schools are present. Equilibrium utility is given by $U^{*}(b, y)=U\left(y_{t}, a\left(q_{v}, b\right)\right)$, where t satisfies $\overline{\mathrm{ty}}=\mathrm{I}_{\mathrm{v}}+\left[\mathrm{V}\left(\mathrm{k}^{*}\right)+\mathrm{F}\right] / \mathrm{k}^{*}$.

To prove Proposition 3, two lemmas are useful:

Lemma 1. Any student who attends private school chooses a school of highest quality among those willing to admit the student (including "the" public school if it exists).

Proof of Lemma 1. Given that private schools must accept exactly the student's voucher as tuition and public schools are free, Lemma 1 follows from utility maximization.

Lemma 2. The highest quality private school has $I=I, \theta=\bar{b}, q=q_{v}, k=k^{*}$, and $\pi=0$.

Proof of Lemma 2. Letting $\mathrm{q}_{\mathrm{s}}$ denote the quality of the second highest quality school in equilibrium, we can write the profit maximization problem of the highest quality private school as:

$$
\begin{gathered}
\operatorname{MAX}_{\mathrm{L}, \alpha(\mathrm{b}, \mathrm{y})} \int_{\mathrm{S}} \int_{\mathrm{V}} \mathrm{v}(\mathrm{b}) \alpha(\mathrm{b}, \mathrm{y}) \mathrm{f}(\mathrm{b}, \mathrm{y}) \mathrm{dbdy}-\mathrm{V}\left(\iint_{\mathrm{S}} \alpha(\mathrm{b}, \mathrm{y}) \mathrm{f}(\mathrm{b}, \mathrm{y}) \mathrm{dbdy}\right) \\
-\mathrm{I} \iint_{\mathrm{S}} \alpha(\mathrm{b}, \mathrm{y}) \mathrm{f}(\mathrm{b}, \mathrm{y}) \mathrm{dbdy}-\mathrm{F} \\
\text { s.t. } \alpha(\mathrm{b}, \mathrm{y}) \in[0,1] \forall(\mathrm{b}, \mathrm{y}) \text { and } \\
\mathrm{q}\left(\iint_{\mathrm{S}} \mathrm{b} \alpha(\mathrm{b}, \mathrm{y}) \mathrm{f}(\mathrm{b}, \mathrm{y}) \mathrm{dbdy} / \iint_{\mathrm{S}} \alpha(\mathrm{b}, \mathrm{y}) \mathrm{f}(\mathrm{b}, \mathrm{y}) \mathrm{dbdy}, \mathrm{l}\right) \geq \mathrm{q}_{\mathrm{s}}
\end{gathered}
$$

where we have written $\theta$ and $\mathrm{k}$ as functions of the school's admission policy (and we omit a subscript for this school's variables). Given that the private school in question is the highest quality, it is innocuous to impose the second constraint. Also, given that the school is of the 
highest quality, any type is willing to attend the highest quality school by Lemma 1 . This justifies the minimal restrictiveness of the first constraint.

Problem (10) has first-order conditions:

$$
\begin{gathered}
\mathrm{q}-\mathrm{q}_{\mathrm{s}} \geq 0 \\
\lambda\left(\mathrm{q}-\mathrm{q}_{\mathrm{s}}\right)=0 \\
\lambda \geq 0 \\
\alpha(\mathrm{b}, \mathrm{y})\left(\begin{array}{c}
=1 \\
\in[0,1]) \\
=0
\end{array}\right) \text { if } \mathrm{v}(\mathrm{b})\left(\begin{array}{l}
> \\
= \\
<
\end{array}\right) \text { EMC; } \\
\mathrm{EMC} \equiv \mathrm{V}^{\prime}+\mathrm{I}+\lambda \frac{\mathrm{q}_{\theta}}{\mathrm{k}}(\mathrm{b}-\theta)
\end{gathered}
$$

where $\lambda$ is the multiplier on the second constraint. The inequality constraint (11.1) binds. If not, $\lambda=0$ and (11.4) would imply a corner solution with $\mathrm{I}=0$ which obviously cannot hold. Further, (11.4) implies $\lambda>0$. Substituting from (11.4) into (11.6), EMC can be rewritten:

$$
E M C=V^{\prime}+I+\frac{q_{\theta}}{q_{I}}(\theta-b)
$$

Assume for the moment that $\mathrm{q}_{\mathrm{s}}=\mathrm{q}_{\mathrm{v}}$. Then the first-order conditions are satisfied by admission 
1. The reason that private schools are homogeneous here, while not so without the tuition restriction (i.e., in Section 5), is that schools must be able to price discriminate with respect to income to gain by differentiating themselves. As the Proof of Proposition 2 shows, profitable differentiation relative to homogeneity entails engendering a higher quality school with a richer clientele; or the reverse. Profits increase e.g. with the former differentiation when schools can charge higher tuition to the richer clientele for the quality increase. The tuition constraint here prevents such profit increases. Note that neither a tuition ceiling nor floor at the level of the voucher would itself prevent stratification. Consider the possibility of equal-quality schools. Under a tuition ceiling, schools would still be able to offer discounts (including fellowships), resulting in the emergence of lower-quality schools that serve relatively poor students. Under a tuition floor, schools would still be able to charge more than the voucher, resulting in the emergence of higher-quality schools that serve relatively wealthy students. These one-sided restrictions would limit stratification effects, but both restrictions are needed to prevent stratification. See, also, the next remark.

2. Given a voucher can be conditioned only on ability (i.e., not on income or characteristics of the school) and admission is at the discretion of private schools, the voucher system in (9:1) (9.2) with tuition constraint is the only system that engenders homogeneous private schools with $\mathrm{I}_{\mathrm{v}}$ expenditure per student. Private schools must be willing to admit all types, and this combined with zero profits implies the voucher must equal the relevant EMC for all types. The level of expenditure per student can be varied by the planner, but then the coefficient on $(\bar{b}-b)$ in the voucher specification must be adjusted appropriately (via (9.2)). Note that this implies that a tuition constraint combined with a flat-rate voucher would fail to engender homogenous schools: Every school would try to admit the highest-ability students to create a higher peer measure while intending to reduce expenditure per student to increase profits.

3. An alternative to a tuition constraint is to link the voucher to the admitting school's peer-group measure and expenditure; or combine a voucher with direct controls on private schools. In an 
policy such that $k=k^{*}, I=I$, and $\theta=\bar{b}$. For example, $\alpha(b, y)=k^{*}$ for all $(b, y)$ with $I=I$, satisfies the first-order conditions. Profits are equal to zero at this solution. Given $q_{s}=q_{v}$, the appendix shows that this is in fact the maximizer (i.e., the second-order conditions are satisfied).

Now we complete the proof by showing that, in equilibrium, $\mathrm{q}_{\mathrm{s}}=\mathrm{q}_{\mathrm{v}}$. Write maximized profits as a function of $\mathrm{q}_{\mathrm{s}}, \pi^{*}\left(\mathrm{q}_{\mathrm{s}}\right)$. Applying the Envelope Theorem, $\pi^{*}\left(\mathrm{q}_{\mathrm{s}}\right)=-\lambda<0$. If then $\mathrm{q}_{\mathrm{s}}$ $<q_{v}, \pi^{*}>0$, implying entry. If $q_{s}>q_{v}, \pi^{*}<0$, implying exit. Hence, if there is a private school in equilibrium, it must be that $\mathrm{q}_{\mathrm{s}}=\mathrm{q}_{\mathrm{v}}$, and the top private school behaves as described in the lemma.

We can now prove Proposition 3:

Proof of Proposition 3. Every private school must be of quality $\mathrm{q}_{\mathrm{v}}$. This is because the highest quality private school is willing to admit any type. Hence, utility maximization implies only private schools of quality $\mathrm{q}_{v}$ can exist. Given quality of $\mathrm{q}_{v}$, following the Proof of Lemma 2, every private school has $I=I_{v}, \theta=\vec{b}, k=k^{*}$, and zero profits. Assuming that there are no public schools, it is an equilibrium to have $\mathrm{k}^{*}$ private schools characterized by these values, with also (obviously) tax rate and utilities as described in the Proposition. Any admission polices that yield these values (e.g., $\alpha_{i}(b, y)=k^{*}$ for all $\left.(b, y), i=1,2, \ldots, n\right)$ make up an equilibrium. No public schools would form simply by our assumption that public school would not be demanded when no public schools are present.

No public schools can exist. If there were only public schools, then $\mathrm{q}_{s}<\mathrm{q}_{\mathrm{v}}$, and entry would result. Since any private school must have $\theta=\bar{b}$ in equilibrium, any public schools must have the same peer measure (by market clearance and given their homogeneity). Public schools are then inferior to private schools by our assumption on $\mathrm{I}_{\mathrm{v}}$. Utility maximization then implies only private schools if there are any private schools.

Remarks on Proposition 3: 
earlier version of this paper, we developed the details of these alternatives. The general message is that, if cream-skimming and stratification are to be prevented, then "strings" need to be attached to a voucher policy. While these alternative approaches are equivalent in our model, private schools have incentives to cheat under any of these systems, and the equivalence is likely to break down with monitoring imperfections. This is an important area for further research. It may be that tuition compliance is less costly to enforce than admission and expenditure compliance, favoring the voucher policy we focus on here. It is interesting that the Florida voucher policy has both a tuition constraint and an admission constraint (i.e., accept all applicants with equal probabilities), both clearly intended to prevent cream skimming. 4. We bave assumed that student ability and household income are observable. These variables might be private information suggesting potential adverse selection issues. Under the voucher system in Proposition 3, househoid income is irrelevant so there are no gains to households from misreporting it. Assuming the reported ability is used both to assign the voucher and for admission decisions, trithful ability revelation is also incentive compatible. If ability is determined by examination, there is no incentive to under perform.

5. We have assumed that if there are no public schools, households do not contemplate attending a public school. Since states are obligated to provide education, this may seem unduly restrictive. One way to defend the assumption is to note that if a household elects public school unilaterally, that it might realistically anticipate low quality due to economies of scale and/or lack of political support for quality. Another assumption that is consistent with our findings is that if an individual chooses public school, then he expects all types to choose public school. The issue that one must get around is that high ability students cannot anticipate a higher quality education in public school due to an expectation that their own ability level would be the peer measure. 6. We have ignored the integer problem in the analysis. The epsilon-equilibrium approximation can be applied here as above. 
6. Voluntary Participation. To gain access to better schools and/or to obtain fellowships, students may wish to opt out of the tuition-constrained voucher system. Here we examine the analogue of the latter system but allowing a form of voluntary participation. We show, among other things, that such a voucher program can replace the public school system with a set of competing, equal-quality, and efficient private schools, while preserving the pre-voucher private schools who here opt out of the voucher program. This permits gains in both educational achievement and utility.

We introduce voluntary participation as follows. Any student may refuse the voucher and attend a private school that does not participate in the voucher program, i.e., admits only nonvoucher students. We assume that any school that admits voucher students may admit only voucher students (but all types will be offered a voucher). Ignore public schools for now. The voucher system we analyze is like that in (9.1) - (9.2) with the tuition constraint, but here the peer measure will differ from the population mean ability in general. If $\mathrm{I}_{\mathrm{v}}$ is sufficiently high, then in fact the voucher system (9.1) - (9.2) will satisfy voluntary participation, i.e., no one will opt out. (The latter follows using the fact that after-tax income declines as $t$ rises to increase $L_{v}$ ) But this is likely to require an unrealistically high tax rate. Hence, we focus on cases where some students do opt out.

The voucher is given by:

$$
\begin{gathered}
v(b)=V^{\prime}\left(k^{*}\right)+I_{v}+\eta_{v}\left(\theta_{v}-b\right) ; \\
\eta_{v}=\frac{q_{\theta}\left(\theta_{v}, I_{v}\right)}{q_{I}\left(\theta_{v}, I_{v}\right)}
\end{gathered}
$$

where $\left(\theta_{v} I_{v}\right)$ (hence also $\left.\eta_{v}\right)$ are set by the planner. Consider first the special case where $\theta_{v}=\theta_{0}$ and $I_{v}=I_{v}$ ' is such that $q\left(\theta_{0}, I_{v}^{\prime}\right)=q_{p}\left(\theta_{0}, I_{0}\right)$. This voucher has the same peer measure as in 
to the no-voucher equilibrium. Redistributing the government budget surplus any way that avoids income effects on the equilibrium, i.e., does not affect the allocation into schools and tuitions of nonvoucher schools, would accomplish this. For realistic parameterizations, poorer households with lower-ability students in voucher schools could be untaxed without income effects. The Pareto Improvement derives, of course, from the efficiencies of competitive provision of education. Below we examine computationally the voucher with tax $t_{0}$ and other tax rates that uses all government revenues to improve the quality of voucher schools.

2. We have again ignored the integer (existence) problem in the analysis. By replacing $\mathrm{k}^{*}$ with $\mathrm{k}_{0} / \mathrm{N}_{0}$ in (12.1) and in the equation defining $\mathrm{n}_{\mathrm{v}}$ (in part a of Proposition 4), we obtain the epsilonequilibrium equivalent. $\left(\mathrm{N}_{0}\right.$ is the number of public schools in the no-voucher equilibrium; see PSP.)

3. If public schools are allowed to exist, then there is a set of equilibria with both public and voucher schools each of quality $\mathrm{q}\left(\theta_{0}, I_{\mathrm{v}}{ }^{\prime}\right)$ providing education to students in $\mathrm{S}_{0}$. Any equilibrium with public schools would obviously have a lower budget surplus and would be less efficient. If public schools can only spend as much per student as can voucher schools, then they cannot survive in equilibrium. ${ }^{29}$ For these reasons, we ignore public schools in what follows.

B. Computational Analysis. We see that a voucher properly linked to student ability and with a tuition constraint can inject competition into the provision of education with no.effects on stratification. We now turn to a computational analysis of this voucher policy. Here we continue to assume a simple proportional income tax but further assume all tax revenues are used to improve quality of voucher schools. Specifically, the voucher is of the form (12.1) - (12.2) (with tuition constraint and voluntary participation), but with $\left(\theta_{v}, I_{v}\right)$ set anticipating non-voucher private schools and a balanced budget. The equilibrium can be thought of as a function of the tax rate. Our intent is to quantify the effects of this voucher in the relatively simple setting with proportional income tax. 
public schools in the no-voucher equilibrium and the expenditure the voucher anticipates is set so that quality would also be the same. Let $t_{0}$ denote the tax rate in the no-voucher equilibrium.

The benchmark theoretical result of this section is:

Proposition 4. The tuition-constrained voucher system (12.1) - (12.2) with $\left(\theta_{v}, I_{v}\right)=\left(\theta_{0}, I_{v}{ }^{\prime}\right)$, satisfying voluntary participation, and financed with tax rate $t_{0}$, engenders an equilibrium with the following properties:

a. $n_{v}=\iint_{S} f(b, y) d b d y / k$ * voucher schools, each with $\theta=\theta_{0}, I=I_{v}$, zero profits, and indifferent to admitting any type;

b. a set of non-voucher private schools exactly as in the no-voucher, public-private schooling equilibrium;

c. student selection into schools as in the no-voucher, public-private schooling equilibrium, but with public-school students in the latter equilibrium attending voucher schools in the present equilibrium; and

d. a government budget surplus (assumed to not be redistributed).

Proof of Proposition 4. Given part a, parts b, c, and d are immediate (parts b and $\mathrm{c}$ by analogy to the no-voucher, public-private schooling equilibrium). Showing part a closely parallels the Proof of Lemma 2 and the first paragraph of the Proof of Proposition 4, so we just outline the argument. If it is assumed that $\mathrm{q}_{s}=\mathrm{q}\left(\theta_{0}, \mathrm{I}_{\mathrm{v}}^{\prime}\right)$ in (10), then, following the analysis in the Proof of Lemma 2 , it is profit maximizing for a voucher school to choose $\theta=\theta_{0}$ and $I=I_{v}$. Zero profits and indifference to admission of any types also follows. Moreover, while the first constraint in (10) would not be met for student types attending non-voucher private schools, it is consistent with the profit-maximizing admission policy we have described. The rest then follows as in these proofs.

Remarks on Proposition 4:

1. A corollary of Proposition 4 is that the voucher system permits a Pareto Improvement relative 
students, but with somewhat larger proportionate gains to lower-income households. Highincome households with high-ability students who remain in the most elite non-voucher schools lose slightly. This is because reduced competition from the other two elite schools that exit allows the remaining elite schools to earn somewhat higher profits in the epsilon competitive equilibrium.

Table 4 reports summary results for the tuition-constrained voucher for the two tax rates just discussed and for a third tax rate that is halfway between the above two rates. Note that the intermediate tax rate leads nearly everyone to gain on both welfare measures relative to the novoucher equilibrium.

7. Concluding Remarks. In this paper, we have emphasized the potential for designing voucher programs that inject private-school competition into the educational system to realize productivity gains but without exacerbating stratification between schools by income and ability. While the real cost of schooling decreases with ability through a peer effect, a laissez-faire voucher linked to ability would fail to accomplish these goals. "Strings" need to be attached to the voucher policy. We focus here on adding to the ability-linked voucher a requirement that the voucher be accepted as tuition, precluding kickbacks or topping up by participating schools. We show such a voucher can accomplish our goals, permitting everyone or almost everyone to have higher educational achievement at no cost.

We believe that the same general strategies can be used to design voucher programs that promote racial integration in schools if this is chosen as a policy objective. Moreover, we believe such an approach would be more effective and less heavy handed than approaches such as mandatory busing of students. Consider the following variation of our model. Suppose that preferences are race blind, but that income and school-age "ability" are positively correlated (because household income is an input to school-age "ability") and that the distribution of whites' income exceeds that of non-whites as defined by stochastic dominance. In a laissez-faire public- 
We examine first a tax rate equal to $4.66 \%$, this the tax rate that will induce a set of competing voucher schools attended by (virtually) the same number of students attending public schools in the no-voucher equilibrium. The associated allocation, the boundary between the voucher and non-voucher private schools, is plotted as one of the lower diagonal lines in Figure 3. As expected and evident in this figure, this boundary is virtually indistinguishable from the public-private boundary in the no-voucher equilibrium. The percentage effects on normed achievement are summarized in the bottom panel of Table 1 . The achievement effects are very small since the gains from improved effectiveness and efficiency of the private-sector schools are used to reduce educational expenditures and, thereby, reduce the tax rate. The effects on compensating variation of introducing this tuition-constrained voucher are summarized in the bottom panel of Table 2 . All households gain approximately $1 \%$ of their incomes. Hence, there is a Pareto Improvement by either welfare measure, although here largely manifest in noneducational gains due to imposing the lower tax rate.

Consider next the equilibrium that arises when the tax rate is retained at its pre-voucher level of $5.6 \%$. The upper diagonal line in Figure 3 is the boundary between voucher schools and non-voucher schools with this tax rate. Attendance in voucher schools in this equilibrium is. $93 \%$. This compares to attendance of $88.5 \%$ in the public sector in the absence of this voucher. Introduction of this voucher leads to exit by two private non-voucher schools. The effects on normed achievement and compensating variation (as a proportion of income) are presented in Table 3. Approximately $90 \%$ of students gain in achievement. All those initially in the public sector attend higher-quality voucher schools with gains in normed achievement of about $3.8 \%$. Recalling that these gains can be interpreted as proportional changes in future income, the gains are substantial. Achievement losses accrue to students who switch from private non-voucher schools to voucher schools. The improvement in the quality of the voucher schools relative to the initial public alternative, both of which have zero net tuition, draws in these students. Approximately $94 \%$ of households experience utility increases, including most of the latter 
private equilibrium, non-whites will be over represented in weaker schools due to their lower incomes. All our results apply to this model: A voucher linked to ability with tuition constraint would increase integration as the tax rate is increased with gains to everyone initially in the public sector. If racial types have a preference for grouping together in schools, then, assuming the social objective continues to be to integrate, vouchers would need to be linked to racial composition of schools. ${ }^{30}$ Whether such a voucher policy would entail elements of affirmative action, meaning different voucher levels for members of different racial groups, is an important issue. The quantification of departures from equal racial treatment with race-neutral vouchers is another important issue. Among other open questions are the effects of such voucher policies on integration and their affirmative action characteristics when government budget limits impose binding constraints on voucher systems.

Still another question is comparison of outcomes under voucher programs relative to neighborhood public schooling equilibria both when race is and is not a factor. In this paper, we have simplified by considering a homogeneous public sector as would arise with frictionless open enrollment. Elsewhere (Epple and Romano, forthcoming), we investigate stratification in neiglborhood public-school systems and in open-enrollment systems with frictions in exercising choice. The kind of voucher policies considered in this paper would likely yield larger gains to low-income and low-ability households when introduced in a stratified public system than when introduced in the homogeneous public-school system considered in this paper. Studying these issues is a subject of our ongoing research.

How voucher systems can be expected to change stratification patterns is an important issue. Whether stratification increases or decreases, our analysis indicates that stratification patterns in systems dominated by voucher-supported students may vary widely with the form of the program. 


\section{$\underline{\text { References }}$}

Arcidiacono, Peter and Sean Nicholson, "The Mirage of Peer Effects: Evidence from U.S. Medical Schools," mimeo, Duke University, 2000.

Bearse, Peter, Glomm, Gerhard and Ravikumar, B., "Education Finance in a Multidistrict Economy," October 1996, mimeo.

Belfield, Clive R. and Levin, Henry M., "The Effects of Competition on Educational Outcomes: A Review of U.S. Evidence," National Center for the Study of Privatization in Education," Columbia University, March 2002.

Benabou, Roland, "Equity and Efficiency in Human Capital Investment: The Local Connection," Review of Economic Studies, April 1996a, 63(2), pp. 237-264. "Heterogeneity, Stratification, and Growth: Macroeconomic Implications of
Community Structure and School Finance," American Economic Review, June 1996b, 86(3), pp.
584-609.

Betts, Julian R. and Darlene Morell, "The Determinants of Undergraduate GPA: The Relative Importance of Family Background, High School Resources, and Peer Group Effects," Journal of Human Resources, v. 107 (1992), 797-817.

Black, Sandra, "Do Better Schools Matter: Parental Valuation of Elementary Education," Quarterly Journal of Economics, May 1999, 114(2), pp. 577-600.

Caucutt, Elizabeth, "Educational Vouchers When There Are Peer Group Effects -- Size Matters," International Economic Review, February 2002, 43 (1), $195-222$.

Chen, Zhiqi and West, Edwin G., "Selective Versus Universal Vouchers: Modelling Median Voter Preferences in Education," American Economic Review, December 2000, 90(5), 1520 1534.

Chubb, John E. and Moe, Terry M., Politics, Markets, and America's Schools, Washington, DC: Brookings Institution, 1990.

Coleman, James S. et.al., Equality of Educational Opportunity, Washington, DC: U.S. Government Printing Office, 1966.

de Bartolomé, Charles A.M., "Equilibrium and Inefficiency in a Community Model with Peer Group Effects," Journal of Political Economy, February 1990, 98(1), pp. 110-133.

Ding, Weili and Steven Lehrer, "Do Peers Affect Student Achievement in China's Secondary Schools?" Working Paper University of Pittsburgh, 2001.

Eden, Benjamin, "How To Subsidize Education And Achieve Voluntary Integration: An Analysis Of Voucher Systems," University of Iowa Working Paper, 1992.

Epple, Dennis, Figlio, David and Richard Romano, "Competition Between Private and Public Schools: Testing Stratification and Pricing Predictions," University of Florida, October 1998. 
Epple, Dennis, Newlon, Elizabeth, and Richard Romano, "Ability Tracking, School Competition, and the Distribution of Educational Benefits," Journal of Public Economics, January 2002, 83 (1), pp. 1-48.

Epple, Dennis and Richard Romano, "Neighborhood Schools, Choice, and the Distribution of Educational Benefits," The Economics of School Choice, Caroline Hoxby ed., National Bureau of Economic Research, forthcoming.

, "Ends Against the Middle: Determining Public Service Provision When There Are Private Alternatives," Journal of Public Economics, November 1996, 62(3), pp. 297-325.

, "Competition Between Private and Public Schools, Vouchers, and Peer-Group Effects." American Economic Review, March 1998, 62(1), pp. 33-62.

Epple, Dennis, Romano, Richard and Sieg, Holger, "Peer Effects, Financial Aid, and Selection of Students into Colleges and Universities: An Empirical Analysis," Journal of Applied Econometrics, forthcoming (a).

, "On the Demographic Composition of Colleges and Universities in Market Equilibrium, American Economic Review Papers and Proceedings, forthcoming (b), May 2002. 1999. ,"Theory and Evidence on Competition in U.S. Higher Education," working paper,

, "Admission, Tuition, and Financial Aid Policies in the Market of Higher Education in Equilibrium," working paper, 2002.

Evans, William N., Oates, Wallace E. and Robert M. Schwab, "Measuring Peer Group Effects: A Study of Teenage Behavior," Journal of Political Economy, v. 100 (1992), 966-991.

Evans, William N. and Schwab, Robert M., "Finishing High School and Starting College: Do Catholic Schools Make a Difference?" Quarterly Journal of Economics, November 1995, 110(4), pp. 941-74.

Fernandez, Raquel and Rogerson, Richard, "Income Distribution, Communities, and the Quality of Public Education: A Policy Analysis," Quarterly Journal of Economics, February 1996,111(1), pp.135-164.

, "Public Education and Income Distribution: A Dynamic Quantitative Evaluation of Education-Finance Reform;" American Economic Review, September 1998, 88(4), pp. 813-33.

Figlio, David and Stone, Joe, "Are Private Schools Really Better?" Research in Labor Economics. Solomon Polachek, ed., 1999, 115-140.

Friedman, Milton, Capitalism and Freedom, Chicago: University of Chicago Press, 1962.

Glomm, Gerhard and Ravikumar, B., "Vouchers, Public and Private Education, and Income Distribution," December 1995, Thomas Jefferson Center for Political Economy Discussion Paper 268, University of Virginia. 
, "Opting Out of Publicly Provided Services: A Majority Voting Result," Social Choice and Welfare, February 1998, 15(2), pp. 187-199.

Gradstein, Mark and Justman, Moshe, "Education Vouchers Versus Public Schooling: Growth, Inequality, and Popularity," mimeo, September 1997.

Grogger, Jeff and Neal, Derek, "Further Evidence on the Benefits of Catholic Schooling," Brookings-Wharton Papers on Urban Affairs, 2000, 151-193.

Henderson, V., P. Mieszkowski, and Y. Sauvageau, "Peer Group Effects in Educational Production Function," Journal of Public Economics, 10, 1978, 97-106.

Hoyt, William and Lee, Kangoh, "Educational Vouchers, Welfare Effects, and Voting," Journal of Public Economics, 1998, 69, pp. 211-28.

Hoxby, Caroline M., "Peer Effects in the Classroom: Learning From Gender and Race Variation," NBER Working Paper No. 7867, August 2000.

, "Does Competition Among Public Schools Benefit Students and Taxpayers? Evidence from Natural Variation in School Districting," American Economic Review, December 2000, v. $90(5), 1209=1238$.

Manski, Charles F., "Educational Choice (Vouchers) and Social Mobility," Economics of Education Review, December 1992, 11(4), pp. 351-369.

Manski, Charles F., "Identification of Endogenous Social Effects: The Reflection Problem," Review of Economic Studies, 40 (1993), 531-542.

McMillan, Robert, "Heterogeneity, Competition, and Public Sector Productivity," mimeo, University of Toronto, February 1998.

Nechyba, Thomas J., "School Finance Induced Migration and Stratification Patterns: The Impact of Private School Vouchers," Journal of Public Economic Theory, 1999, 1(1), pp. 5-50.

March 2000, 90 (1), pp. 130-146.

, “Centralization, Fiscal Federalism, and Private School Attendance," International

Economic Review, forthcoming.

Rangazas, Peter, "Vouchers and Voting: An Initial Estimate Based on the Median Voter Model," Public Choice, 1995, 82 (nos. 3-4), pp. 261-279.

Roberston, D. and J. Symons, "Do Peer Groups Matter? Peer Group versus Schooling Effects on Academic Attainment," London School of Economics Centre for Economic Performance Discussion Paper No. 331 (1996).

Scotchmer, Suzanne, "Public Goods and Invisible Hand," in J. Quigley and E. Smolensky, eds., Modern Public Finance, Cambridge, MA: Harvard University Press, 1994, pp. 98-119.

$+$ , "On Price-Taking Equilibria in Club Economies with Nonanonymous 
Crowding," Journal of Public Economics, June 1997, 65(1), pp. 75-87.

Scotchmer, Suzanne and Wooders, Myrna H., "Competitive Equilibrium and the Core in Club Economies with Nonanonymous Crowding, Journal of Public Economics, November 1987, 34(2), pp. 159-173.

Solon, Gary, "Intergenerational Income Mobility in the U.S.," American Economic Review, June 1992, Vol. 82, No. 3, 393-409.

Summers, Anita and Barbara L. Wolfe, "Do Schools Make a Difference?" American Economic Review, 67 (September 1977), No. 4, 639-652.

Zimmer, Ron and Eugenia Toma, "Peer Effects in Private and Public Schools: Across Country Empirical Analysis," University of Kentucky Working Paper, May 1997.

Zimmerman, David J., "Peer Effects in Academic Outcomes: Evidence from a Natural Experiment," Williams Project on the Economics of Higher Education Discussion Paper No. 52, 1999.

Zimmerman, David J., "Regression Toward Mediocrity in Economic Stature," American Economic Review, Vol. 82, No. 3, June 1992, 409-429. 


\section{Footnotes.}

1. Nechyba also examines targeting of vouchers to poor jurisdictions. See also Chen and West (2000) who examine political support for vouchers targeted to the relatively poor in a model without peer effects in education.

2. Another key difference is our attention to the issue of voluntary participation (see Section 6), from which Eden abstracts by not permitting the co-existence of a laissez-faire private system.

3. Evidence supporting the empirical relevance of our model of public-private school competition is provided in Epple, Figlio, and Romano (1998). That paper conducts extensive tests of the stratification and pricing predictions of our model and finds strong support for those predications.

4. There is a large, growing, and controversial literature on peer effects by social scientists. Early studies are Coleman (1966), Henderson, Mieszkowski, and Sauvageau (1978), and Summers and Wolfe (1977). Here we mention just some of the subsequent empirical studies by economists that are most closely related to our model. Most of the literature on peer effects on educational success concern primary and secondary education. Manski (1993a) details the several difficulties in empirically identifying peer effects. Evans, Oates, and Schwab (1992) find no peer effects in schools predicting teenage pregnancy or drop-out once selection is taken into account. Robertson and Symons (1996), Zimmer and Toma (1997), Hoxby (2000), and Ding and Lehrer (2001) are more recent studies that find evidence of peer effects on educational success. Turning to research on peer effects in higher education, Sacerdote (2001) and Zimmerman (1999) find peer effects between roommates on giade point averages. Betts and Morell (1999) find that high-school peer groups affect college grade point average. Arcidiacono and Nicholson (2000) find no peer effects among medical students.

5. Heterogeneous public schools are discussed in Section 7.

6. See, for examples, Evans and Schwab (1995), Figlio and Stone (1999), Grogger and Neal (2000), Belfield and Levin (2002).

7. The educational production function $q(\theta, I)$ is then that of private schools. Note that in the Cobb-Douglas specification we use in the computational analysis, these two effects can be combined into a single productivity parameter.

8. The number of schools that minimizes public schooling costs is independent of the value of I in the public sector.

9. Analysis of alternative objective functions to profit maximization is of interest given the significant proportion of nonprofit schools. Some private schools might, for example, pursue the objective of quality maximization. Epple, Sieg, and Romano (1999, 2002, forthcoming-a, forthcoming-b) develop a model of competing educational quality maximizers and apply it to estimate equilibrium in U.S. undergraduate higher education. Competitive pressures lead equilibrium to be very similar to that with profit maximizers. We characterize private schools as 
profit maximizers here to facilitate comparison to the rest of the literature on vouchers and because a large scale voucher program can be reasonably expected to lead to entry of a substantial number of for-profit schools.

10. Public voucher proposals and policies are typically designed to have neutral effects on per student expenditure in public schools as, for example, in the Florida program. We do not mean, however, to trivialize the issues that arise regarding public choice of educational inputs. See de Bartolome (1990), Benabou (1996,1997),-Chen and West (2000), Epple and Romano (1996, forthcoming), Fernandez and Rogerson $(1996,1998)$, Glomm and Ravikumar $(1995,1997)$, and Nechyba (1998,2000, forthcoming) for models where public choice of educational expenditure plays a key role.

11. Student types $(b, y)$ indifferent between attending either public or private schools will be of measure zero in our applications unless noted otherwise.

12. Friedman's (1962) voucher system would let "[p]arents ... spend this sum and any additional sum on purchasing educational services from an "approved" institution of their own choice ... [and] ... educational services could be rendered by private enterprises for profit, or by non-profit institutions [including publicly run schools] (p. 89)." The approval requirement was envisioned to be minimal, as Friedman compared it to government inspection of "... restaurants to insure they maintain minimum sanitary standards (p. 89)." Chubb and Moe (1990) describe "... a system in which government would provide funding directly to students in the form of vouchers and students would use vouchers to pay for education in the public or private school of their choosing (p. 217)."

13. The net cost of attending private school i equals $p_{i}-v$.

14. The epsilon equilibrium is consistent with the presence of "epsilon inefficient" private schools, but, for simplicity, we abstract from this. We assume all private schools are cost efficient and maximally effective as if $\epsilon=0$.

15. Note that utility can be written as a function of achievement or normed achievement: $U\left(y_{t^{-}}\right.$ $\mathrm{p}, \mathrm{a})=\mathrm{U}\left(\mathrm{y}_{\mathrm{t}}-\mathrm{p}, \mathrm{a}_{\mathrm{N}}^{\beta}\right)$.

16. Current expenditure per student in public schools in 1997 was $\$ 5,882$, and capital expenditure was 11.9\% of current expenditure (Public Education Finances, 1997 from 1997

Census of Governments, Volume 4, Government Finances. Issued May 2000, GC97(4)-1, Tables 8 and 9). Together these imply a total of $\$ 6,582$ per student. Inflation from 1997 to 2000 was approximately $7 \%$ implying expenditure per student of approximately $\$ 7,000$.

17. Our estimate of $50 \%$ custodial costs is based on the cost of day care for the same number of hours as in a typical school year. Details are available on request.

18. Technically, along boundary loci, students are indifferent so attendance at the higher quality school implies only weakly higher income. 
19. The weak ascension of the $\eta$ 's along the quality hierarchy is not necessary for ability stratification. But it is an intuitive condition and we have found it to hold in a variety of computations. Having said this, we have also found exceptions to ability stratification in related analyses. Keep in mind that the strict hierarchy result and income stratification always hold.

20. The adjacent private school discounts to ability while, obviously, the public school does not. This implies that as ability rises, there is a preference for the lower-quality private school, which is offset by higher income along the relevant (upward-sloping) boundary locus.

21. We did not use the proportion in public schools to calibrate our model, but our equilibrium proportion of $88.5 \%$ is very close to the observed value in 1998 of $88.75 \%$ (Statistical Abstract 2001, Table 205).

22. A policy that requires private schools to have per student expenditure at least equal to the voucher would eliminate bottom-feeder schools and cream skimming as we define it would worsen.

23. Part of the reduced educational achievement is due to lower average expenditure in private schools that enter relative to the expenditure in the (now eliminated) public sector. In fact, in aggregate, there is about a $1 \%$ achievement loss from the $\$ 7,000$ voucher. Poorer students prefer lower expenditure and kickbacks from schools. We discuss further below normative perspectives on our findings.

24. The finding that $85 \%$ have a welfare gain from the flat-rate voucher contrasts to the finding in our earlier paper (1998) that less than a majority gain. The broader appeal of the flat-rate voucher in our analysis here is attributable to the higher productivity of private schools and to more substantial tuition changes because schooling expenditure can vary.

25. By a "nondegenerate joint distribution" we mean a joint distribution whose associated conditional distributions are atomless.

26. $\mathrm{v}^{*}(\mathrm{~b})$ would need to equal the EMC(b) that arises in the resulting homogeneous schools. We derive similar results to this below.

27. This is the shadow value of ability assuming homogeneous schools and expenditure per student of $\$ 7,000$.

28. Other changes to the equilibrium conditions are simple and will be made clear.

29. Again, the issue arises about how students evaluate a public-school alternative if none are present but public education must be provided on demand.

30. This is analogous to linking the voucher to other school peer-group measures, like mean ability. As noted above, we analyzed this alternative as a substitute for the tuition constraint in an earlier version of this paper. 
FIGURE 1

ADMISSIONSPACES WITHFLAT-RATE VOUCHER
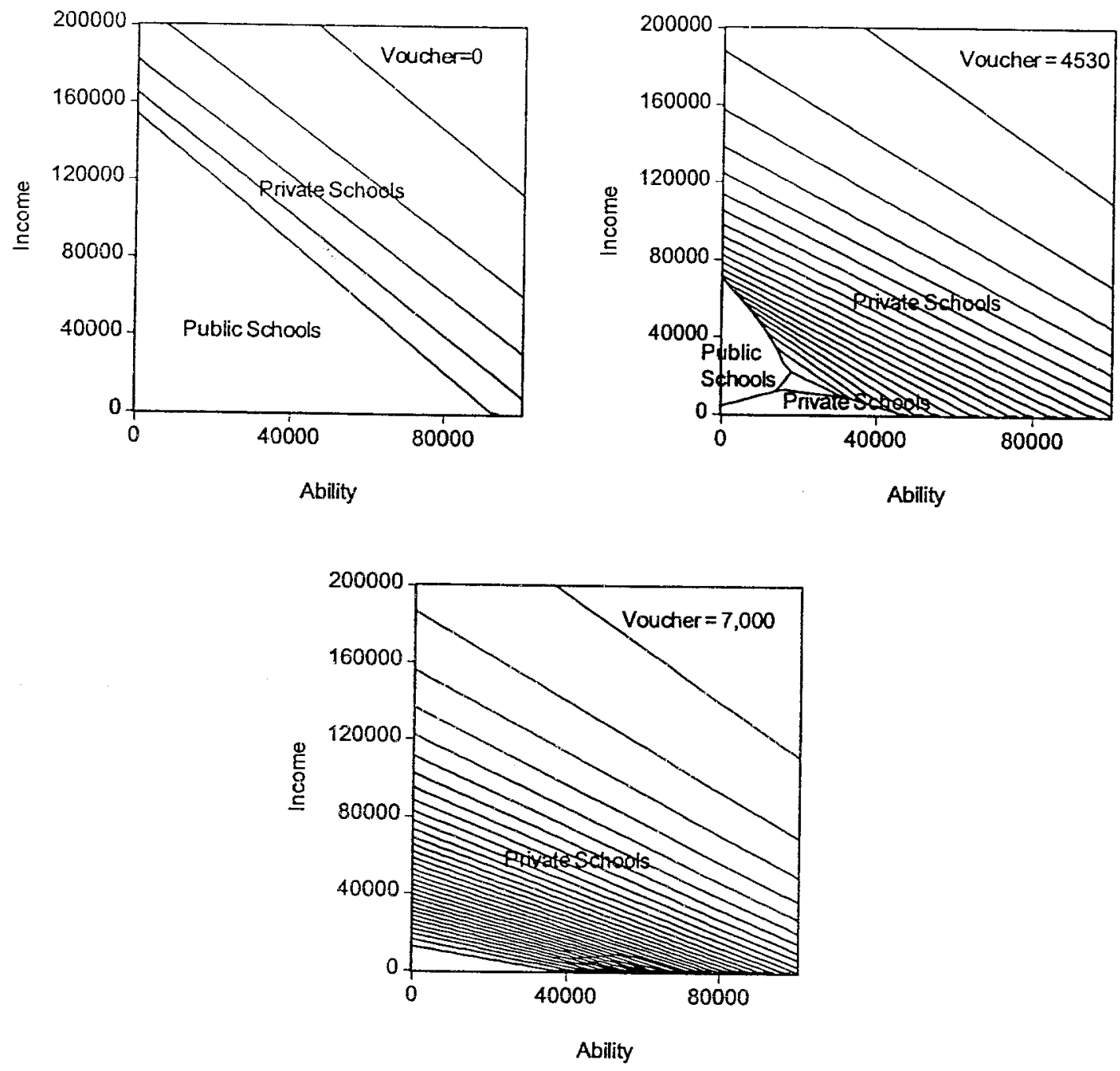
FIGURE 2

ADMISSION SPACES WITH ABILITY-DEPENDENT VOUCHER
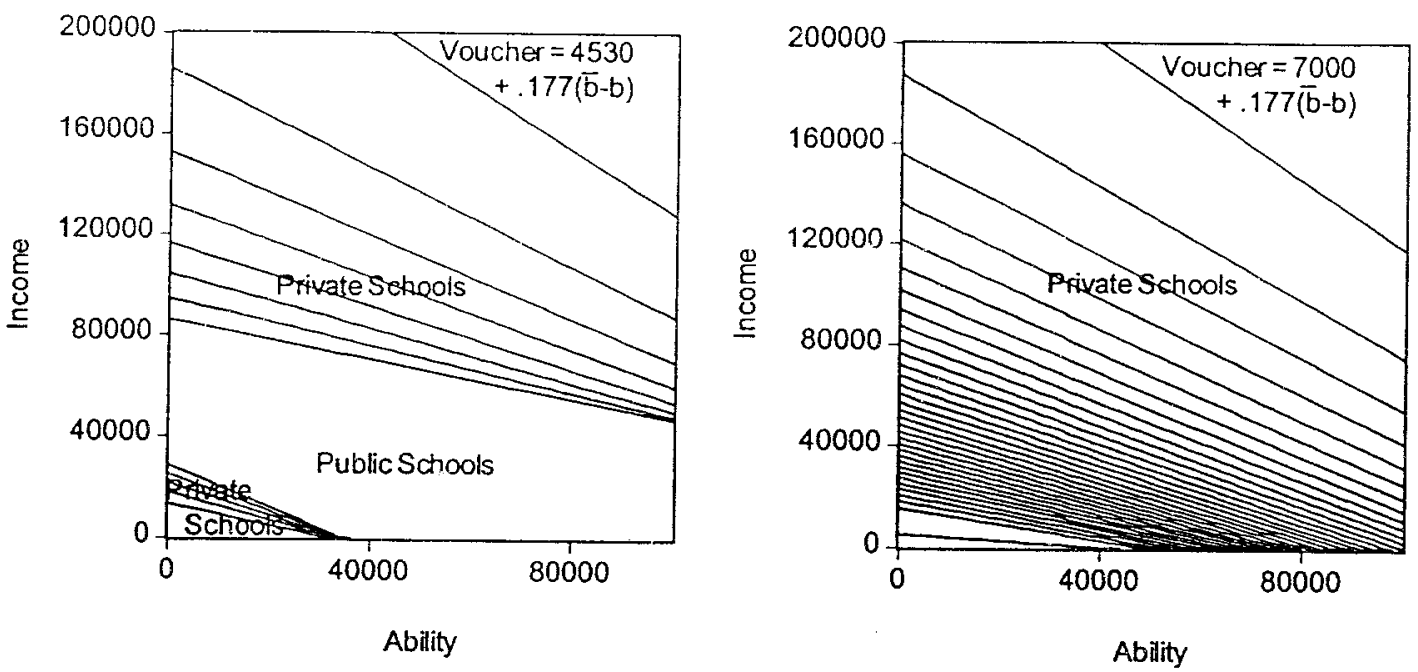


\section{FIGURE 3}

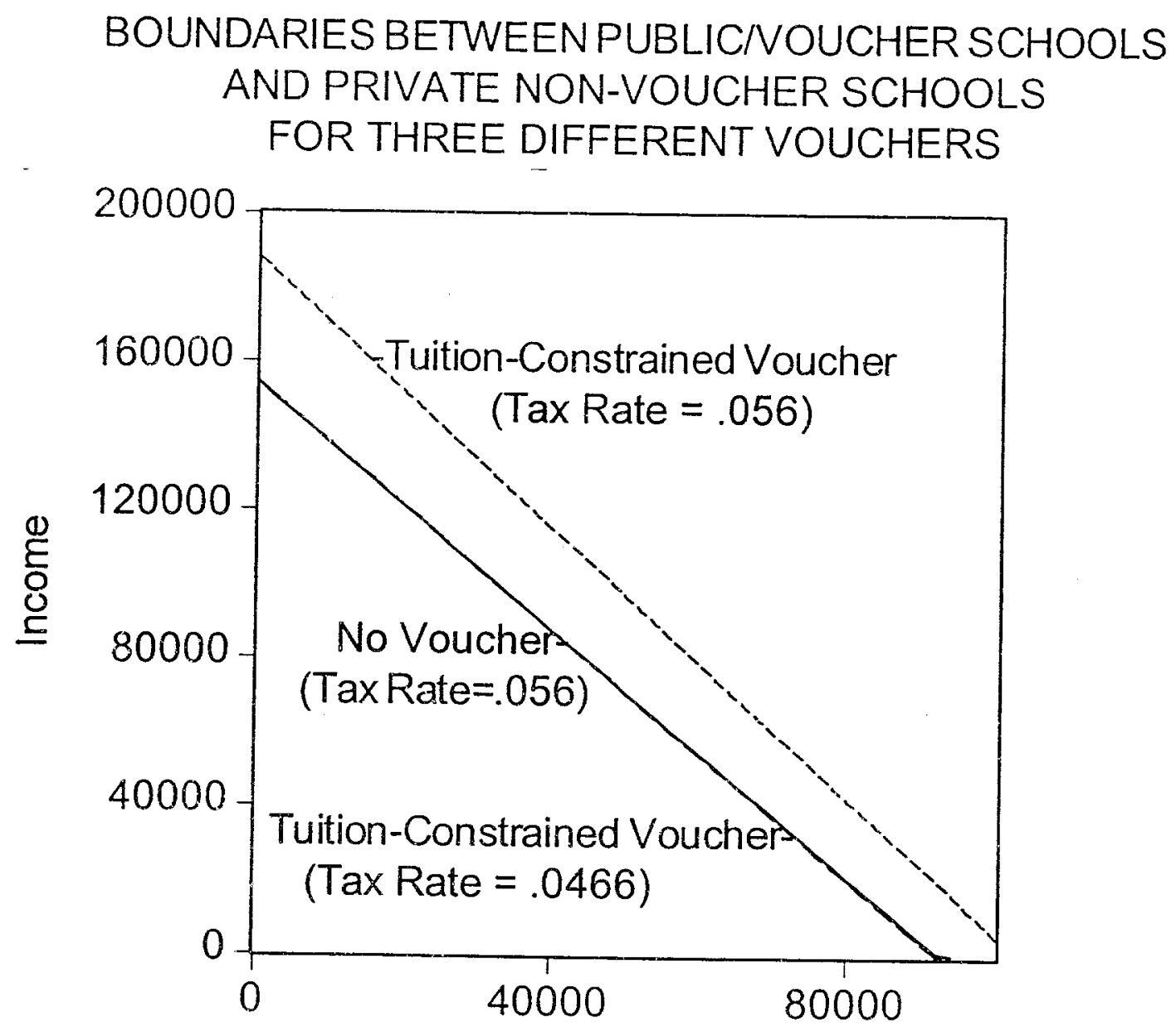

Ability 
TABLE 1

AVERAGE PERCENTAGE CHANGE IN NORMED ACHIEVEMENT

THREE VOUCHER SYSTEMS COMPARED TO NO-VOUCHER EQUILIBRIUM

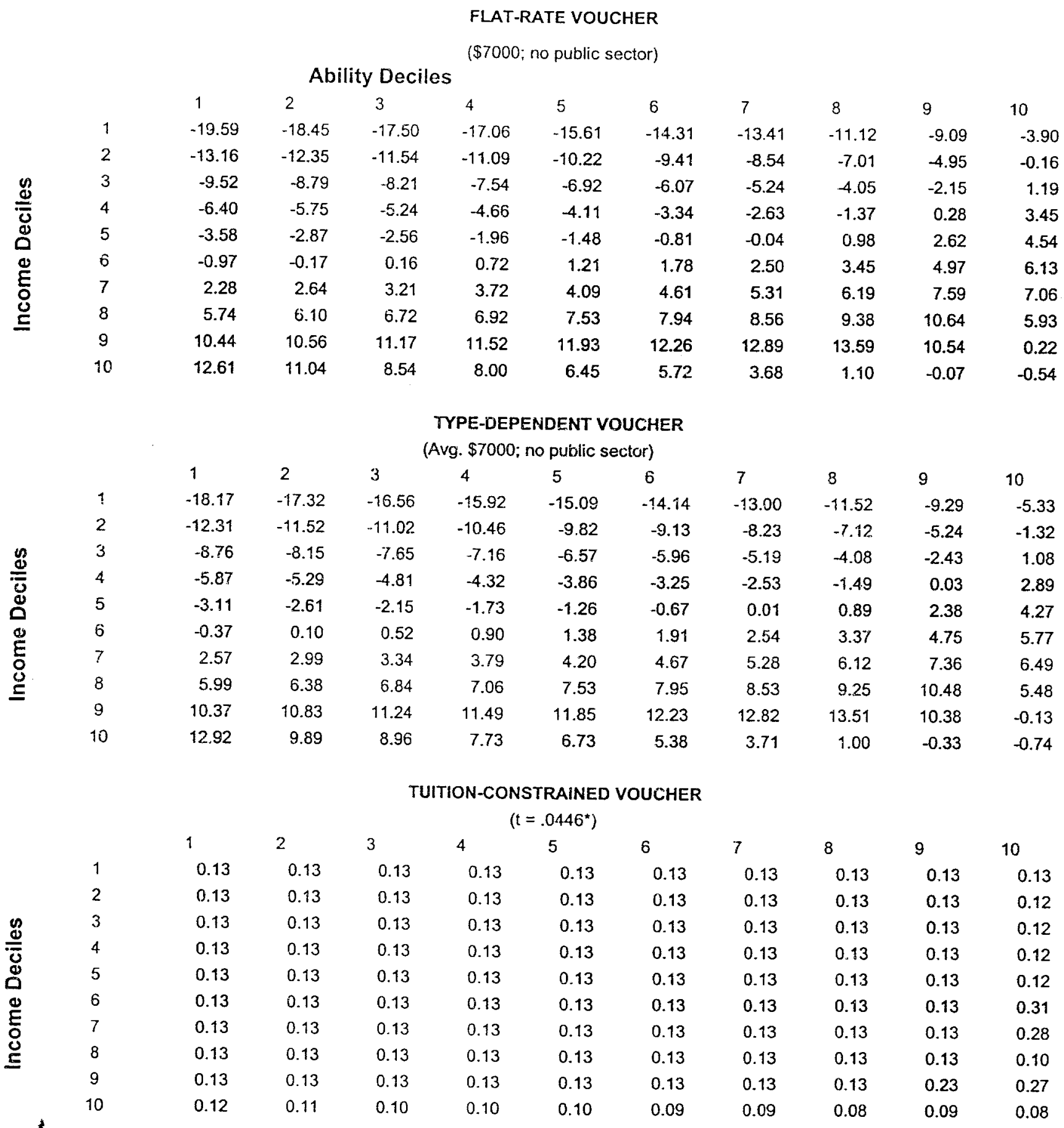

"The tax rate is such that voucher schools serve same number of students as public sector in benchmark equilibrium. 
TABLE 2

AVERAGE COMPENSATING VARIATION AS PERCENT OF INCOME

THREE VOUCHER SYSTEMS COMPARED TO NO-VOUCHER EQUILIBRIUM

\title{
FLAT-RATE VOUCHER
}

(\$7000; no public sector)

\begin{abstract}
Ability Deciles
\end{abstract}

1
-2.87
-3.16
-2.84
-2.45
-1.97
-1.53
-0.89
-0.24
0.72
1.90
2

$-1.73$

$$
-2.46
$$

$-2.29$

$-1.94$

$-1.55$

$-1.11$

$-0.62$

0.04

0.90

2.08

3

$\begin{array}{ll}-0.92 & 0.01 \\ -1.91 & -1.36 \\ -1.82 & -1.34 \\ -1.56 & -1.15 \\ -1.22 & -0.85 \\ -0.82 & -0.49 \\ -0.32 & -0.03 \\ 0.32 & 0.52 \\ 1.15 & 1.35 \\ 2.19 & 2.25\end{array}$

\begin{tabular}{r}
\multicolumn{1}{l}{5} \\
0.58 \\
-0.74 \\
-0.83 \\
-0.71 \\
-0.47 \\
-0.15 \\
0.26 \\
0.81 \\
1.57 \\
2.34
\end{tabular}

6

6
1.53
0.00
-0.22
-0.18
-0.01
0.26
0.62
1.09
1.82
2.42

7

3.42

8

0.89

0.55

0.48

0.57

0.77

1.07

1.49

2.14

2.55

TYPE-DEPENDENT VOUCHER

(Avg. \$7000; no public sector)

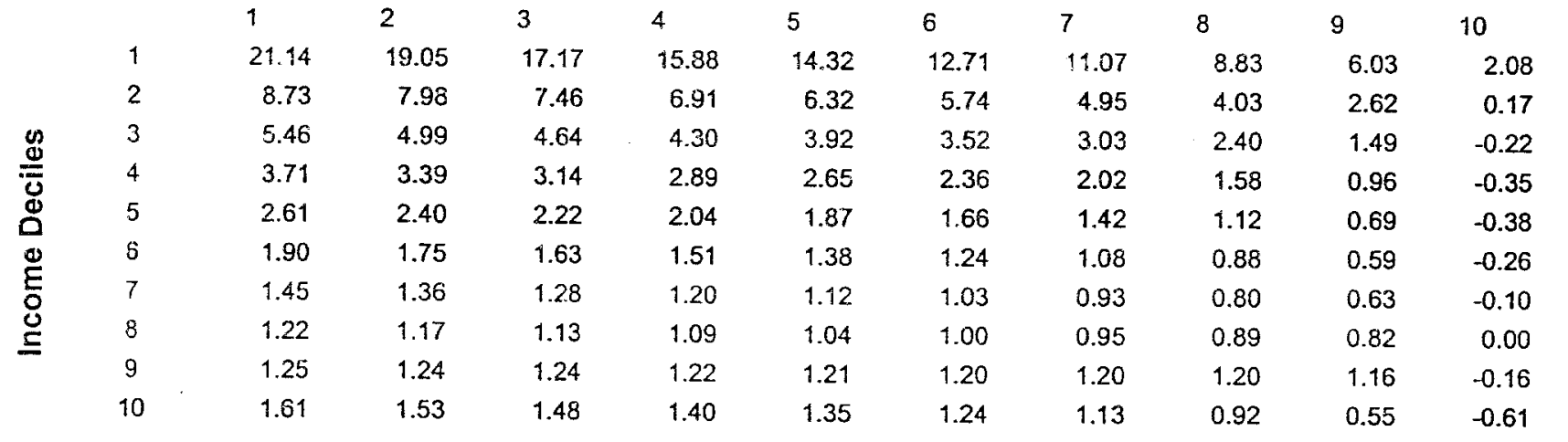

TUITION-CONSTRAINED VOUCHER

\begin{tabular}{|c|c|c|c|c|c|c|c|c|c|c|}
\hline & 1 & 2 & 3 & 4 & 5 & 6 & 7 & 8 & 9 & 10 \\
\hline 1 & 0.99 & 0.99 & 0.99 & 0.99 & 0.99 & 0.99 & 0.99 & 0.99 & 0.99 & 0.99 \\
\hline 2 & 0.99 & 0.99 & 0.99 & 0.99 & 0.99 & 0.99 & 0.99 & 0.99 & 0.99 & 1.01 \\
\hline$g$ & 0.99 & 0.99 & 0.99 & 0.99 & 0.99 & 0.99 & 0.99 & 0.99 & 0.99 & 1.00 \\
\hline 4 & 0.99 & 0.99 & 0.99 & 0.99 & 0.99 & 0.99 & 0.99 & 0.99 & 0.99 & 1.00 \\
\hline 5 & 0.99 & 0.99 & 0.99 & 0.99 & 0.99 & 0.99 & 0.99 & 0.99 & 0.99 & 1.00 \\
\hline $\mathscr{E}$ & 0.99 & 0.99 & 0.99 & 0.99 & 0.99 & 0.99 & 0.99 & 0.99 & 0.99 & 1.00 \\
\hline 7 & 0.99 & 0.99 & 0.99 & 0.99 & 0.99 & 0.99 & 0.99 & 0.99 & 0.99 & 0.99 \\
\hline 8 & 0.99 & 0.99 & 0.99 & 0.99 & 0.99 & 0.99 & 0.99 & 0.99 & 0.99 & 0.99 \\
\hline 9 & 0.99 & 0.99 & 0.99 & 0.99 & 0.99 & 0.99 & 0.99 & 0.99 & 0.98 & 0.98 \\
\hline 10 & 0.98 & 0.97 & 0.96 & 0.96 & 0.96 & 0.96 & 0.95 & 0.95 & 0.95 & 0.96 \\
\hline
\end{tabular}

\footnotetext{
*The tax rate is such that the voucher schools serve same number of students as public sector in benchmark equilibrium.
} 
TABLE 3

\author{
AVERAGE CV AS PERCENTAGE OF INCOME \\ AND \\ AVERAGE PERCENTAGE CHANGE IN ACHIEVEMENT \\ TUITION-CONSTRAINED VOUCHER WITH \\ TAX RATE SAME AS IN NO VOUCHER EQUILIBRIUM
}

COMPENSATING VARIATION

\begin{tabular}{|c|c|c|c|c|c|c|c|c|c|c|}
\hline & & $A b$ & Deci & & & & & & & \\
\hline & 1 & 2 & 3 & 4 & 5 & 6 & 7 & 8 & 9 & 10 \\
\hline 1 & 1.05 & 1.05 & 1.05 & 1.05 & 1.05 & 1.05 & 1.05 & 1.05 & 1.05 & 1.05 \\
\hline 2 & 1.05 & 1.05 & 1.05 & 1.05 & 1.05 & 1.05 & 1.05 & 1.05 & 1.05 & 0.74 \\
\hline 3 & 1.05 & 1.05 & 1.05 & 1.05 & 1.05 & 1.05 & 1.05 & 1.05 & 1.05 & 0.91 \\
\hline 4 & 1.05 & 1.05 & 1.05 & 1.05 & 1.05 & 1.05 & 1.05 & 1.05 & 1.05 & 0.89 \\
\hline 5 & 1.05 & 1.05 & 1.05 & 1.05 & 1.05 & 1.05 & 1.05 & 1.05 & 1.05 & 0.75 \\
\hline 6 & 1.05 & 1.05 & 1.05 & 1.05 & 1.05 & 1.05 & 1.05 & 1.05 & 1.05 & 0.81 \\
\hline 7 & 1.05 & 1.05 & 1.05 & 1.05 & 1.05 & 1.05 & 1.05 & 1.05 & 1.05 & 0.74 \\
\hline 8 & 1.05 & 1.05 & 1.05 & 1.05 & 1.05 & 1.05 & 1.05 & 1.05 & 1.05 & 0.54 \\
\hline 9 & 1.05 & 1.05 & 1.05 & 1.05 & 1.05 & 1.05 & 1.05 & 1.05 & 0.98 & 0.09 \\
\hline 10 & 0.85 & 0.79 & 0.72 & 0.63 & 0.6 & 0.55 & 0.45 & 0.3 & 0.06 & -0.16 \\
\hline
\end{tabular}

\title{
NORMED ACHIEVEMENT
}

\begin{tabular}{|c|c|c|c|c|c|c|c|c|c|c|c|}
\hline \multirow{11}{*}{ 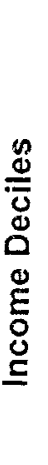 } & & 1 & 2 & 3 & 4 & 5 & 6 & 7 & 8 & 9 & 10 \\
\hline & $\hat{\imath}$ & 3.79 & 3.79 & 3.79 & 3.79 & 3.79 & 3.79 & 3.79 & 3.79 & 3.79 & 3.79 \\
\hline & 2 & 3.79 & 3.79 & 3.79 & 3.79 & 3.79 & 3.79 & 3.79 & 3.79 & 3.79 & 3.17 \\
\hline & 3 & 3.79 & 3.79 & 3.79 & 3.79 & 3.79 & 3.79 & 3.79 & 3.79 & 3.79 & 3.02 \\
\hline & 4 & 3.79 & 3.79 & 3.79 & 3.79 & 3.79 & 3.79 & 3.79 & 3.79 & 3.79 & 3.37 \\
\hline & 5 & 3.79 & 3.79 & 3.79 & 3.79 & 3.79 & 3.79 & 3.79 & 3.79 & 3.79 & 2.27 \\
\hline & 6 & 3.79 & 3.79 & 3.79 & 3.79 & 3.79 & 3.79 & 3.79 & 3.79 & 3.79 & 2.11 \\
\hline & 7 & 3.79 & 3.79 & 3.79 & 3.79 & 3.79 & 3.79 & 3.79 & 3.79 & 3.79 & 1.60 \\
\hline & 8 & 3.79 & 3.79 & 3.79 & 3.79 & 3.79 & 3.79 & 3.79 & 3.79 & 3.79 & -0.66 \\
\hline & 9 & 3.79 & 3.79 & 3.79 & 3.79 & 3.79 & 3.79 & 3.79 & 3.79 & -0.08 & -5.04 \\
\hline & 10 & 2.14 & -0.42 & -1.18 & -1.00 & -2.95 & -2.45 & -3.92 & -5.07 & -3.41 & 0.05 \\
\hline
\end{tabular}


Table 4

TUITION CONSTRAINED VOUCHER
WITH THREE DIFFERENT TAX RATES

1

2

3

Tax Rate

Input Per Student

Attendance in Voucher Schools

CV Gain Per Capita

$\%$ With CV Gain

\begin{tabular}{|c|c|c|c|}
\hline \multirow{2}{*}{$\begin{array}{l}4.66 \% \\
2,320\end{array}$} & $5.13 \%$ & & $5.61 \%$ \\
\hline & 2,740 & $\$$ & 3,180 \\
\hline $88.5 \%$ & $90.8 \%$ & & $92.7 \%$ \\
\hline $0.96 \%$ & $0.89 \%$ & & $0.77 \%$ \\
\hline $100.0 \%$ & $99.8 \%$ & & $93.8 \%$ \\
\hline $0.13 \%$ & $1.45 \%$ & & $2.70 \%$ \\
\hline $100.0 \%$ & $96.0 \%$ & & $89.9 \%$ \\
\hline
\end{tabular}

Column 1: Tax rate that yields attendance in voucher schools equal to public school attendance in no-voucher equilibrium.

Column 3: Tax rate same as in no-voucher equilibrum.

Column 2: Tax rate halfway between columns (1) and (3). 


\section{Appendix for "Educational Vouchers and Cream Skimming" Dennis Epple and Richard Romano}

Proof of Proposition 1. The results in Proposition 1 generalize the results in Propositions 1 - 3 of Epple and Romano (1998) to allowing variation across schools in I. Much of the proof here follows the proofs in the latter paper.

1. Strict Hierarchy. First we show the strict hierarchy result for the private schools by contradiction. Suppose that $q_{i}=q_{j}$ for private schools $i$ and $j$. Then $E M C_{i}(b)=E M C_{j}(b)$ for all b. To see this, suppose not. For appropriate assignment of $i$ and $j$, the linearity of $E M C(b)$ in $b$ would imply either: (i) there exists a b' such that $\left.\mathrm{EMC}_{\mathrm{i}}(\mathrm{b})>(<) \Leftrightarrow\right) \mathrm{EMC}_{\mathrm{j}}(\mathrm{b})$ for $\left.\mathrm{b}<(>) \Leftrightarrow\right) b^{\prime}$; or (ii) $\mathrm{EMC}_{\mathrm{i}}(\mathrm{b})>\mathrm{EMC}_{\mathrm{j}}(\mathrm{b})$ for ail $\mathrm{b}$. In case (i), using that every type would have the same reservation price for attending schools $i$ or $j$, the admission criterion (8.3) and market clearance imply no type with $b<(>)$ b' would attend school $i(j)$. Hence, $\theta_{i}>\theta_{j}$. Since $q_{i}=q_{j}$, then $I_{i}<I_{j}$. Using (8.5) and quasiconcavity of $q(\theta, I)$, then $\eta_{i}<\eta_{j}$. Hence, using (8.4), $\mathrm{EMC}_{\mathrm{i}}(\mathrm{b})$ is flatter in $\mathrm{b}$ than $\mathrm{EMC}_{\mathrm{j}}$ (b), contradicting (i).

In case (ii), the admission criterion and market clearance imply no types attend school i, contradicting existence of school i. Having established that $\mathrm{EMC}_{\mathrm{i}} \equiv \mathrm{EMC}_{\mathrm{j}}(\mathrm{b})$, it is further implied that the schools are identical with respect to the relevant variables $(\theta, I, \mathrm{k})$.

Now we show a contradiction to profit maximization by demonstrating that either school could with local deviation increase its profits. Suppose first that the attendance spaces of schools $i$ and $j$ overlap with positive measure in the $(b, y)$ plane. Then we show that school $i$ can increase profits by admitting a measure $\Delta_{1}$ of students of type $\left(b_{1}, y_{1}\right)$ while expelling the same measure $\Delta_{2}$ $\bar{\sigma}-\Delta_{1}$ of students of type $\left(b_{2}, y_{2}\right)$, where either: (iii) $b_{1} \geq b_{2}$ and $y_{1}>>y_{2}$; or (iv) $b_{1} \leqslant b_{2}$ and $y_{1} \ll<$ 
$y_{2}$. Here the newly admitted students are attracted from school $j$. If the attendance spaces of schools $i$ and $j$ do not overlap initially, then school i first expels half of each type of its students and admits half of each type of school j's students. (The latter would have no effect on profits as we clarify below.) Then the student substitutions in (iii) or (iv) are feasible.

To compute the effect on profits from such a student substitution, observe that initially $\mathrm{p}_{\mathrm{i}}{ }^{*}\left(\mathrm{~b}, \mathrm{y}_{\mathrm{t}}+\mathrm{v}, \mathrm{q}_{\mathrm{i}}\right)=\mathrm{p}_{\mathrm{j}}{ }^{*}\left(\mathrm{~b}, \mathrm{y}_{\mathrm{t}}+\mathrm{v}, \mathrm{q}_{\mathrm{j}}\right)=\mathrm{EMC}_{\mathrm{i}}(\mathrm{b})=\mathrm{EMC}_{\mathrm{j}}(\mathrm{b})$ for all students attending schools $\mathrm{i}$ and $\mathrm{j}$. If $\mathrm{p}^{*}>\mathrm{EMC}$, market clearance is violated $\left(\alpha_{\mathrm{i}}+\alpha_{\mathrm{j}}>1\right)$. If $\mathrm{p}^{*}<\mathrm{EMC}$, then the student cannot attend $\mathrm{i}$ or $\mathrm{j}$. This implies the first-order effect of expelling or admitting any students initially in school $i$ or $j$ vanishes. (It is also implied that profits are unchanged by expelling half of each type and admitting half of the other school's students. This would not change $\mathrm{q}_{\mathrm{i}}, \mathrm{k}_{\mathrm{i}}$, or $\mathrm{EMC}_{\mathrm{i}}(\mathrm{b})$, and tritions would continue to equal $\mathrm{EMC}_{\mathrm{i}}(\mathrm{b})$.) Let $\pi_{\mathrm{t}}^{\mathrm{i}}$ denote the first-order effect on profits of schooi $i$ of changing the measure of type $t$ students in school $i$, and $\pi_{\mathrm{tt}}^{i}$ the second-order effect. Using Taylor's Theorem, for $\Delta_{1}=-\Delta_{2}$ small, the sign of the change in profits $\left(\Delta \pi_{\mathrm{i}}\right)$ from a student substitution is given by the sign of:

$$
\begin{gathered}
\pi_{1}^{\mathrm{i} \Delta_{1}+}+\pi_{2}^{\mathrm{i} \Delta_{2}}+\frac{1}{2}\left[\pi_{11}^{\mathrm{i}}\left(\Delta_{1}\right)^{2}+\pi_{22}^{\mathrm{i}}\left(\Delta_{2}\right)^{2}+2 \pi_{12}^{\mathrm{i}} \Delta_{1} \Delta_{2}\right] \\
=\frac{1}{2}\left[\pi_{11}^{\mathrm{i}}\left(\Delta_{1}\right)^{2}+\pi_{22}^{\mathrm{i}}\left(\Delta_{2}\right)^{2}+2 \pi_{12}^{\mathrm{i}} \Delta_{1} \Delta_{2}\right] \\
=\frac{1}{2}\left(\Delta_{1}\right)^{2}\left[\pi_{11}^{\mathrm{i}}+\pi_{22}^{\mathrm{i}}-2 \pi_{12}^{\mathrm{i}}\right] .
\end{gathered}
$$

The first equality in (A1) follows since the first-order effects vanish, and the second equality since the student substitution is designed so that $\Delta_{1}=-\Delta_{2}$.

- Using (A1), with straightforward calculation, one obtains: 


$$
\begin{gathered}
\operatorname{sign}\left[\Delta \pi_{\mathrm{i}}\right]= \\
\operatorname{sign}\left\{\frac{2}{\mathrm{k}_{\mathrm{i}}}\left(\mathrm{b}_{1}-\mathrm{b}_{2}\right) \frac{\partial \mathrm{q}}{\partial \theta_{\mathrm{i}}}\left[\frac{\partial \mathrm{p}_{\mathrm{i}}{ }^{*}\left(\mathrm{y}_{1 \mathrm{t}}+\mathrm{v}, \mathrm{b}_{1}, \mathrm{q}_{\mathrm{i}}\right)}{\partial \mathrm{q}}-\frac{\partial \mathrm{p}_{\mathrm{i}}^{*}\left(\mathrm{y}_{2 \mathrm{t}}+\mathrm{v}, \mathrm{b}_{2}, \mathrm{q}_{\mathrm{i}}\right)}{\partial \mathrm{q}}\right]\right. \\
\left.+\left(\frac{\mathrm{b}_{1}-\mathrm{b}_{2}}{\mathrm{k}_{\mathrm{i}}}\right)^{2} \iint_{\mathrm{S}} \frac{\partial^{2} \mathrm{p}_{\mathrm{i}}^{*}}{\partial \theta_{\mathrm{i}}^{2}} \alpha_{\mathrm{i}} \mathrm{fdbdy}\right\}
\end{gathered}
$$

Suppose that $b_{1} \geq b_{2}$ and $y_{1} \gg y_{2}$. Then the first term after the equality in (A2) is positive by (SCI). Moreover, the first term dominates the second term, since, given $b_{1}<b_{2}$ and $y_{1}$ is not approximately equal to $y_{2}$, the second term is of lower order than the first term. The same holds for $b_{1} \leqslant b_{2}$ and $y_{1} \ll y_{2}$. This establishes the strict hierarchy of private schools.

That $\mathrm{q}_{0}<\mathrm{q}_{1}$ when $\mathrm{v}=0$ follows simply because net tuition $\mathrm{p}_{\mathrm{i}}-\mathrm{v}=\mathrm{p}_{\mathrm{i}}$ is positive for at least some students in every private school while public schooling is free. That $\mathrm{q}_{0}>\mathrm{q}_{\mathrm{i}}$ for $\mathrm{i} \geq 1$ is possible when $v>0$ is illustrated in our computational analysis.

2. Pricing. a. Using that any private school $\mathrm{j}$ is willing to admit any student at tuition $\mathrm{EMC}_{\mathrm{j}}(\mathrm{b})$, a continuous function, and that public schooling is free, (5) and the definition of $\mathrm{p}_{\mathrm{i}}{ }^{*}\left(\mathrm{y}_{\mathrm{t}}+\mathrm{v}, \mathrm{b}, \mathrm{q}_{\mathrm{i}}\right)$ imply it is a continuous function. $\left(\mathrm{U}_{\mathrm{i}}^{*}(\mathrm{~b}, \mathrm{y})\right.$ is continuous for all $\mathrm{i}$ and $(\mathrm{b}, \mathrm{y})$.) If not $\mathrm{p}_{\mathrm{i}}=\mathrm{EMC}_{\mathrm{i}}$ on a boundary locus of private school $i$, then either: (i) $p_{i}<E M C_{i}$; or (ii) $p_{i}>E M C_{i}$. If (i), using continuity of $p_{i}{ }^{*}$, then $p_{i}{ }^{*}<E M C_{i}$ just within school $i$ 's admission space, a contradiction to the admission criterion. If (ii), using continuity, then $\mathrm{p}_{\mathrm{i}}{ }^{*}>\mathrm{EMC}_{\mathrm{i}}$ just outside the boundary locus in another school j's admission space. Then $\alpha_{i}=1$ and $\alpha_{i}+\alpha_{j}>1$, violating market clearance.

b. As argued in part a, $\mathrm{p}_{\mathrm{i}}<E M \mathrm{EC}_{\mathrm{i}}$ could not hold. If $\mathrm{p}_{\mathrm{i}}=E \mathrm{EMC}_{\mathrm{i}}$, then we must be on a boundary locus of private school i. To establish this, use SCI and observe that EMC(b) is independent of $y$ 
at any school implying either: (iii) $\partial \mathrm{p}_{\mathrm{i}}{ }^{*} / \partial \mathrm{y}>0$ (if the best alternative school of types in the vicinity of the initial point $(\mathrm{b}, \mathrm{y})$ is of lower quality than $\mathrm{q}_{\mathrm{q}}$ ); or (iv) $\partial \mathrm{p}_{\mathrm{i}}{ }^{*} / \partial \mathrm{y}<0$ (if the best alternative school of types in the vicinity of the initial point $(b, y)$ is of higher quality than $q)$. In case (iii), those of marginally lower income than the student for whom $\mathrm{p}_{\mathrm{i}}=\mathrm{EMC}_{\mathrm{i}}$ would attend another school. In case (iv), those of marginally higher income than the student for whom $p_{1}=$ $\mathrm{EMC}_{\mathrm{i}}$ would attend another school. Hence, it must be that $\mathrm{p}_{\mathrm{i}}>\mathrm{EMC}_{\mathrm{i}}$ in the interior of school i's admission space. Since $\mathrm{p}_{\mathrm{i}}=\mathrm{p}_{\mathrm{i}}{ }^{*}\left(\mathrm{~b}, \mathrm{y}_{\mathrm{i}}+\mathrm{v}, \mathrm{q}_{\mathrm{i}}\right)$, the dependence on both $\mathrm{b}$ and $\mathrm{y}$ follows. (Note that the linkage of $\mathrm{p}_{\mathrm{i}}^{*}$ to $\mathrm{b}$ is not driven by a positive ability elasticity of demand for quality. For example, consider the Cobb-Douglas preferences in (1) which has zero ability elasticity of demand for quality. Here, $\mathrm{p}_{\mathrm{i}}^{*}\left(\mathrm{~b}, \mathrm{y}_{\mathrm{t}}+\mathrm{v}, \mathrm{q}_{\mathrm{i}}\right)$ decreases with ability for all students having another private school as their best alternative because EMC(b) in their best alternative school declines with ability.)

c. The alternative must have a student attend school $\mathrm{i}$ when there exists private school $\mathrm{j}$ such that $\mathrm{U}\left(\mathrm{y}_{\mathrm{t}}+\mathrm{v}-\mathrm{EMC}_{\mathrm{j}}, \mathrm{a}\left(\mathrm{q}_{\mathrm{j}}, \mathrm{b}\right)\right)>\mathrm{U}\left(\mathrm{y}_{\mathrm{t}}+\mathrm{v}-\mathrm{EMC} \mathrm{C}_{\mathrm{i}}, \mathrm{a}\left(\mathrm{q}_{\mathrm{i}}, \mathrm{b}\right)\right)$, where we adopt the convention that $\mathrm{v}=\mathrm{EMC}_{\mathrm{i}}=0$ if $i=0$ (is a public-sector school). Since $p_{i} \geq E M C_{i}$ for students attending school $i, U\left(y_{t}+v-\right.$ $\left.\mathrm{EMC}_{\mathrm{j}}, \mathrm{a}\left(\mathrm{q}_{\mathrm{j}}, \mathrm{b}\right)\right)>\mathrm{U}\left(\mathrm{y}_{\mathrm{t}}+\mathrm{v}-\mathrm{p}_{\mathrm{i}}, \mathrm{a}\left(\mathrm{q}_{\mathrm{i}}, \mathrm{b}\right)\right)$. Given $\mathrm{i}$ is attended, it must be a best alternative to school $\mathrm{j}$, with the latter inequality implying $\mathrm{p}_{\mathrm{j}}{ }^{*}>\mathrm{EMC}_{\mathrm{j}}$. This implies $\alpha_{\mathrm{j}}=1$, contradicting market clearance (i.e., $\alpha_{j}+\alpha_{i}>1$ ).

3. Stratification. a. Given Proposition 1-2c (i.e., the last result) and that public schools are free, the allocation can be determined by prices that are independent of income. Using SCI, income stratification then follows by a standard "single-crossing argument." 
b. We again use Proposition 1-2c and a single-crossing argument. For the case of $\mathrm{v}=0$, let $p_{i}{ }^{d} \equiv V^{\prime}\left(k_{i}\right)+I_{i}+\theta_{i} \eta_{i}, i=1,2, \ldots, n$. Let $p_{0}{ }^{d} \equiv \eta_{0} \equiv 0$. For predicting school choices, by Proposition 1-2c, utility of type (b,y) attending school i, i $=0,1, \ldots, n$, may be calculated as:

$\mathrm{U}=\mathrm{U}\left(\mathrm{y}_{\mathrm{t}}+\eta_{\mathrm{i}} \mathrm{b}-\mathrm{p}_{\mathrm{i}}{ }^{\mathrm{d}}, \mathrm{a}\left(\mathrm{q}_{\mathrm{i}}, \mathrm{b}\right)\right)$. Hence, choice across the $\mathrm{n}+1$ schools is as though students face typeindependent prices $p_{i}{ }^{d}$ and have incomes $y_{t}+\eta_{i} b$. Given weak ascension of the $\eta_{i}$ 's along the quality hierarchy, weak single-crossing in ability, and SCI, stratification by ability then arises by a single-crossing argument. (Note that with zero ability elasticity of demand and $\eta_{1}=\eta_{2}=\ldots=$ $\eta_{\mathrm{n}}$, ability stratification results due to the income effect of the same discounting to ability across the set of private schools. That is, higher ability students effectively are richer if any private school is attended so that ability stratification is implied by SCI.)

If $v>0$, then $q_{0}>q_{i}$ for some $i \geq 1$ is possible as seen in the computational analysis. Figure XX shows that ability stratification along the quality hierarchy can be violated between the public school and the adjacent worse private school. The reason is that EMC(b) declines with ability in the private school, but not in the public school, so that relative utility in the private versus public school may rise with ability. (In fact, it necessarily does for Cobb-Douglas preferences, but this need not hold for utility with positive ability elasticity of demand for quality.)

Proof of Sufficiency of Profit Maximum in Lemma 2. At the solution to the first-order conditions in the Proof of Lemma 2, the first constraint does not bind and can be ignored and the second constraint binds. Given the latter, it is convenient to eliminate the choice of I by solving the second constraint for $\mathrm{I}: \mathrm{I}=\hat{\mathrm{I}}(\theta(\alpha(\mathrm{b}, \mathrm{y})))$, where we use this compact notation to indicate that $\hat{\mathrm{I}}$ 
is a functional of the choice of $\alpha(b, y)$ through the latter's determination of $\theta$. (The dependence of $\hat{I}$ on $q_{s}$ can be suppressed since $q_{s}$ does not change.) Hence, write profits in (10):

$$
\begin{aligned}
\pi(\alpha(\mathrm{b}, \mathrm{y})) & =\iint_{\mathrm{S}} \mathrm{v}(\mathrm{b}) \alpha(\mathrm{b}, \mathrm{y}) \mathrm{dbdy}-\mathrm{V}(\mathrm{k}(\alpha(\mathrm{b}, \mathrm{y}))) \\
& -\hat{\mathrm{I}}(\theta(\alpha(\mathrm{b}, \mathrm{y}))) \cdot \mathrm{k}(\alpha(\mathrm{b}, \mathrm{y}))-\mathrm{F}
\end{aligned}
$$

where we similarly write the functional $k(\alpha(b, y))$ for convenience.

Letting $\pi_{\mathrm{i}}$ denote the variation in $\pi$ with respect to type $\left(\mathrm{b}_{\mathrm{i}}, \mathrm{y}_{\mathrm{i}}\right)$, we have ${ }^{\mathrm{t}}$ :

$$
\begin{aligned}
\pi_{i} & =v\left(b_{i}\right)-V^{\prime}-I-\frac{q_{\theta}}{q_{I}}\left(\theta-b_{i}\right) \\
& =v\left(b_{i}\right)-\operatorname{EMC}\left(b_{i} ; k(\alpha(b, y)), \theta(\alpha(b, y))\right) .
\end{aligned}
$$

Our indicating that EMC depends on $\alpha$ through $\mathrm{k}$ and $\theta$ will prove useful below. At the solution to the first-order conditions in Lemma $2, \pi_{\mathrm{i}}=0$ for all types of course. Now compute the second variation, letting $\pi_{i j}$ denote it with respect to types $\left(b_{i}, y_{i}\right)$ and $\left(b_{j}, y_{j}\right)$. After some manipulation one obtains:

$$
\pi_{i j}=-V^{\prime \prime}+\left(\theta-b_{i}\right)\left(\theta-b_{j}\right) Z
$$

hence

$$
\pi_{\mathrm{ii}}=-\mathrm{V}^{\prime \prime}+\left(\theta-\mathrm{b}_{\mathrm{i}}\right)^{2} \mathrm{Z}
$$

where

\footnotetext{
${ }^{1}$ We actually compute the variations with respect to of which are more convenient to work with.
} 


$$
Z \equiv \frac{q_{\theta}^{2} q_{I I}-2 q_{\theta} q_{I} q_{\theta I}+q_{I}^{2} q_{\theta \theta}}{k q_{I}^{3}} .
$$

Quasiconcavity of $q(\theta, I)$ implies the numerator of $(A 7)$ is negative, hence that $Z<0$. Then, $\pi_{i i}<$ 0 . The determinant of the Hessian with respect to variation in two types is given by:

$$
\pi_{i i} \pi_{i j}-\pi_{i j}^{2}=-V^{\prime \prime} Z\left(b_{i}-b_{j}\right)^{2}>0
$$

Hence, the "two-type Hessian" matrix is negative definite, implying a maximum with respect to admissions variations involving one or two types.

We have shown that profits can not be increased by any admissions variations involving one or two types of students. But the effect on profits of admissions variations involving more than two types can always be replicated by an admission variation involving just one or two types. Profit variations from admissions changes work only through the resulting changes in $\mathrm{k}$ and $\theta$, since profit variations derive only from the second variation in $\operatorname{EMC}\left(b_{i} ; k(\alpha(b, y)), \theta(\alpha(b, y))\right)$ (see (A4)). Any variation with both $d \theta$ and dk not equal to zero has a corresponding variation involving just one or two ability types. Letting $\mathrm{dk}_{\mathrm{i}}$ denote the change in admission of type $i$, the implications for $\theta$ and $k$ of changing admission of two types are given by:

$$
\mathrm{d} \theta=\frac{\mathrm{b}_{1}-\theta}{\mathrm{k}} \mathrm{dk}_{1}+\frac{\mathrm{b}_{2}-\theta}{\mathrm{k}} \mathrm{dk}_{2}
$$


Using these, one can engender any pair $(\mathrm{d} \theta, \mathrm{dk})$ if we allow admissions of any types, perhaps

$$
\mathrm{dk}=\mathrm{dk}_{1}+\mathrm{dk}_{2}
$$

including types not in S. But the inability to increase profits by varying up to two types is independent of the nature of S. Hence, if variations involving more than two types could increase profits, we have contradicted the results above for one or two types. 